\title{
Review
}

\section{Targeting Synaptic Dysfunction in Alzheimer's Disease by Administering a Specific Nutrient Combination}

\author{
Nick van Wijk ${ }^{\mathrm{a}, *}$, Laus M. Broersen ${ }^{\mathrm{a}}$, Martijn C. de Wilde ${ }^{\mathrm{a}}$, Robert J.J. Hageman ${ }^{\mathrm{a}}$, \\ Martine Groenendijk ${ }^{\mathrm{a}}$, John W.C. Sijben ${ }^{\mathrm{a}}$ and Patrick J.G.H. Kamphuis ${ }^{\mathrm{a}, \mathrm{b}}$ \\ ${ }^{\mathrm{a} N u t r i c i a}$ Advanced Medical Nutrition, Nutricia Research, Utrecht, The Netherlands \\ ${ }^{\mathrm{b}}$ Utrecht Institute for Pharmaceutical Sciences (UIPS), Utrecht University, Utrecht, The Netherlands
}

Handling Associate Editor: Thomas Shea

Accepted 23 July 2013

\begin{abstract}
Synapse loss and synaptic dysfunction are pathological processes already involved in the early stages of Alzheimer's disease (AD). Synapses consist principally of neuronal membranes, and the neuronal and synaptic losses observed in AD have been linked to the degeneration and altered composition and structure of these membranes. Consequently, synapse loss and membrane-related pathology provide viable targets for intervention in AD. The specific nutrient combination Fortasyn Connect (FC) is designed to ameliorate synapse loss and synaptic dysfunction in AD by addressing distinct nutritional needs believed to be present in these patients. This nutrient combination comprises uridine, docosahexaenoic acid, eicosapentaenoic acid, choline, phospholipids, folic acid, vitamins $\mathrm{B}_{12}, \mathrm{~B}_{6}, \mathrm{C}$, and $\mathrm{E}$, and selenium, and is present in Souvenaid, a medical food intended for use in early $\mathrm{AD}$. It has been hypothesized that $\mathrm{FC}$ counteracts synaptic loss and reduces membrane-related pathology in $\mathrm{AD}$ by providing nutritional precursors and cofactors that act together to support neuronal membrane formation and function. Preclinical studies formed the basis of this hypothesis which is being validated in a broad clinical study program investigating the potential of this nutrient combination in AD. Memory dysfunction is one key early manifestation in AD and is associated with synapse loss. The clinical studies to date show that the FC-containing medical food improves memory function and preserves functional brain network organization in mild AD compared with controls, supporting the hypothesis that this intervention counteracts synaptic dysfunction. This review provides a comprehensive overview of basic scientific studies that led to the creation of FC and of its effects in various preclinical models.
\end{abstract}

Keywords: Alzheimer's disease, amyloid- $\beta$, Fortasyn Connect, membrane, neurotransmission, nutrition, phospholipid, Souvenaid, synaptic dysfunction

\footnotetext{
*Correspondence to: Nick van Wijk, MSc, Nutricia Research, PO Box 80141, 3508 TC Utrecht, The Netherlands. Tel.: +31 30 2095000; Fax: +31 30 2100436; E-mail: nick.vanwijk@ nutricia.com
}

\section{TARGETING MEMBRANE-RELATED PATHOLOGY AND SYNAPTIC LOSS IN ALZHEIMER'S DISEASE}

Membrane-related pathology and synapse loss are central to the pathogenesis of Alzheimer's disease (AD) and therefore represent compelling targets for intervention in this condition. This review discusses 
how nutrients and their specific combinations affect the synthesis and composition of neuronal membranes, leading to improved membrane-dependent processes of potential relevance for patients with $\mathrm{AD}$, such as synaptic functioning.

\section{Synaptic dysfunction in the pathogenesis of $A D$}

$\mathrm{AD}$ is a chronic neurodegenerative disease characterized by a progressive functional decline in memory and other cognitive domains, with the frequent occurrence of non-cognitive behavioral symptoms and impairments in the ability to perform activities of daily living $[1,2]$. While the cause of $\mathrm{AD}$ is unknown, it is widely accepted that multiple genetic and environmental risk factors underlie the development of the disease [2]. Characteristic hallmarks of AD include extracellular amyloid- $\beta$ (A $\beta)$ plaques; intracellular neurofibrillary tangles composed of hyperphosphorylated tau; and a continuous loss of neurons [2, 3]. Additionally, already in the early stages of the disease there is a loss of synapses $[4,5]$ that has been shown to precede and exceed neuronal loss $[6,7]$. A $\beta$ accumulation is considered an upstream event in the cascade that leads to synaptic loss and synaptic dysfunction $[4$, 8-10].

AD-related synapse loss progresses during the course of the disease and leads to a progressive impairment of brain performance and worsening of clinical symptoms $[4,5,11]$. While synaptic loss occurs during normal, non-pathological aging in humans [12], it is far more pronounced in $\operatorname{AD}[12,13]$. This indicates that the disease-induced synaptic loss in $\mathrm{AD}$ occurs in addition to age-related synaptic loss. Based on this, it may be hypothesized that the need for renewal of synapses is greater in AD patients than in normal healthy age-matched individuals. Symptomatic dementia manifests when cortical synapse number is reduced by approximately $40 \%$ or more compared with age-matched cognitively intact adults [14]. Synaptic loss is a direct structural correlate with cognitive test performance in $\mathrm{AD}[14,15]$ and is more robustly correlated with cognitive deficits than the amount of amyloid plaques or neurofibrillary tangles, or the degree of neuronal loss [14]. Studies that also include subjects with mild cognitive impairment (MCI) and mild AD indicate that synaptic loss is an early structural correlate in AD [16-18]. These postmortem findings are in line with imaging biomarker studies in living patients. Although it is not possible to quantify synaptic density and synaptic functioning directly in humans, ${ }^{18} \mathrm{~F}$-fluorodeoxyglucose positron emission tomography (FDG-PET) [19, 20], functional magnetic resonance imaging (fMRI) [21], and electroencephalography (EEG) [22-24] provide useful biomarkers for synaptic dysfunction and network connectivity in AD progression [25]. Such imaging markers indicate that synaptic dysfunction is a pathological process involved already in the early stages of the disease, even prior to the onset of clinical AD, i.e., in a preclinical stage or in subjects with MCI [10]. In fact, these biomarkers help to differentiate between disease stages and are predictive for risk of progression from cognitive normal subjects to $\mathrm{MCI}$ and $\mathrm{AD}$ $[10,26]$.

Synapses and neurites consist principally of neuronal membranes that are composed of phospholipid bilayers structurally integrated with, for example, cholesterol, sphingolipids, and a variety of proteins, including ion-channels, receptors, and enzymes [27]. Proper membrane lipid homeostasis in neurons is essential for preventing the loss of synaptic function [28]. Neuronal and synaptic losses observed in $\mathrm{AD}$ have been linked to the degeneration of neuronal membranes and increased breakdown of membrane phospholipids [29-32]. In addition to the degeneration of neuronal membranes, alterations in membrane composition and structure are observed in patients with $\mathrm{AD}$. Disturbances in phospholipid composition [29-33], levels of plasmalogens [33-35], levels of polyunsaturated fatty acids (PUFAs), particularly docosahexaenoic acid (DHA; $22: 6 n-3)$ [31, 34, 36-39], and the composition of lipid rafts [40] have been observed in the AD brain. Neuronal membrane alterations have also been identified in patients with MCI [41].

The neuronal membrane is the principal site of action for numerous neuronal activities [42]. Biochemical and physical alterations that directly influence the composition and structure of membranes can affect a multitude of membrane-dependent processes [28]. These include receptor and ion channel structure and activity, axonal signal transduction, activity of membrane-bound enzymes, optimal exchange of nutrients and other molecules, and mitochondrial efficiency [42-44]. Thus, membrane degeneration and alteration of membrane structure have a profound impact on neuronal membrane functioning and consequent neuronal functioning.

Taken together, membrane-related pathology and synapse loss play a central role in the pathogenesis of $\mathrm{AD}$, and consequently provide viable interventional targets. Brain structure and function are known to be influenced by nutrients obtained from the diet $[45,46]$. 
In particular, neurons require specific nutrients for the formation and maintenance of neuronal membranes. As described below, increasing the availability of certain nutrients modulates neuronal membrane formation and function. Consequently, dietary supplementation of specific combinations of nutrients potentially reduces membrane-related pathology and synaptic loss in $\mathrm{AD}$ patients.

\section{A specific nutrient combination designed to} support synapse formation and function in patients with $A D$

Fortasyn ${ }^{\circledR}$ Connect (FC) is a specific nutrient combination designed to ameliorate synapse loss and synaptic dysfunction in AD by addressing nutritional needs believed to exist in these patients. This specific nutrient combination is present in Souvenaid ${ }^{\circledR}$, a medical food intended for early AD patients. FC comprises precursors and cofactors needed for the formation and maintenance of neuronal membranes, i.e., uridine (as uridine monophosphate, UMP), the omega-3 PUFAs DHA and eicosapentaenoic acid (EPA; 20 : 5n3 ), choline, phospholipids, folic acid, vitamin $\mathrm{B}_{12}$, vitamin $\mathrm{B}_{6}$, vitamin $\mathrm{C}$, vitamin $\mathrm{E}$, and selenium. The precursors for membrane synthesis (DHA, EPA, uridine, choline, and phospholipids) act by enhancing the substrate-saturation of the enzymes that catalyze the rate-limiting steps of membrane phospholipid synthesis. B-vitamins, vitamin C, vitamin E, selenium, and phospholipids act as cofactors by increasing the availability of membrane precursors or by directly affecting the neuronal membrane or membrane synthesis. A schematic summary of the hypothetical effects of FC on neuronal membranes and synapse formation is presented in Fig. 1. The basic scientific studies presented in this review provide the rationale for this hypothesis and formed the basis for the creation of this specific nutrient combination. Most of these preclinical studies were conducted under supervision of Dr. R.J. Wurtman (Massachusetts Institute of Technology, Cambridge, MA, USA) supported by the National Institutes of Health and the Center for Brain Sciences and Metabolism Charitable Trust. Additional preclinical studies were conducted in collaboration with Dr. A.J. Kiliaan (Radboud University Nijmegen Medical Centre, Nijmegen, The Netherlands); Dr. P.G.M. Luiten, (University of Groningen, Groningen, The Netherlands), and partners within the LipiDiet (EU FP5, QLK-2002-172) and LipiDiDiet (EU FP7, grant $\mathrm{N}^{\circ}$ 211696) projects led by Dr. T. Hartmann (Saarland University, Homburg, Germany).
The aim of this report is to provide a comprehensive overview of basic scientific studies that led to the creation of FC and of its effects in various in vitro and in vivo models. These studies demonstrate that the nutrients in this specific combination act in concert to modulate neuronal membrane formation and function, and consequently affect synapse formation, neurotransmission, A $\beta$-related pathology, and cognitive performance. The potential clinical relevance of these effects is being examined in a broad clinical study program in $\mathrm{AD}$ patients.

\section{EFFECTS OF NUTRITIONAL COMPOUNDS ON NEURONAL MEMBRANE FORMATION AND FUNCTION}

The formation of new neuronal membranes and the maintenance of membrane composition and structure are highly dynamic processes that occur continuously throughout life [28]. These processes rely upon a sustained supply of neuronal membrane precursors and cofactors, largely provided by the diet. Data summarized below indicate that these nutritional compounds can increase neuronal membrane formation and improve membrane functioning.

\section{Precursor control of membrane formation}

The phospholipid bilayer of neuronal membranes is composed of several classes of phospholipids; most common in the mammalian brain are phosphatidylcholine (PC), phosphatidylethanolamine (PE), sphingomyelin (SM), phosphatidylserine (PS), and phosphatidylinositol (PI) [47]. Phospholipids themselves are highly heterogeneous, with each class representing a subset of compounds with differing fatty acid compositions.

PC and PE, the most abundant phospholipids in the brain, are synthesized by the cytidine diphosphate (CDP)-choline pathway and the CDP-ethanolamine pathway, respectively. Together these pathways are also known as the Kennedy pathway. A plain overview of the Kennedy pathway is depicted in Fig. 2, right panel [48]. SM is usually formed from the combination of ceramide and the phosphocholine unit of PC. PS is made via a base-exchange reaction, in which serine is exchanged for the choline or ethanolamine moiety in PC or PE, respectively. The de novo pathway of PI synthesis starts with the formation of CDP-diacylglycerol (DAG) from DAG 3-phosphate and cytidine triphosphate (CTP). The activated DAG unit then reacts with inositol to form PI [49]. 


\section{A specific nutrient combination designed to enhance synapse formation and function}

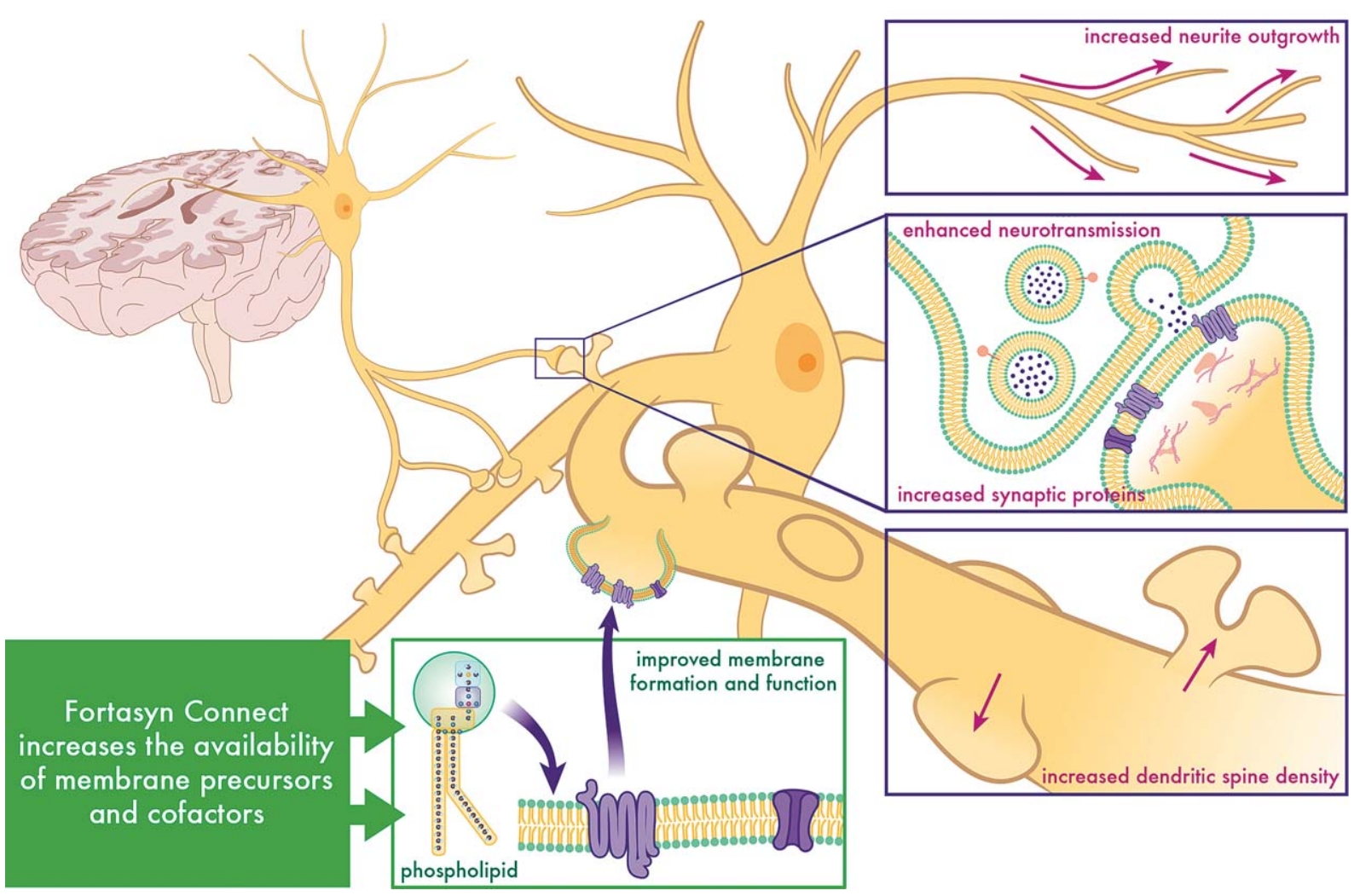

Fig. 1. The formation of new synapses requires the synthesis of new neuronal membranes. Intake of the specific nutrient combination Fortasyn Connect increases the availability of circulating membrane precursors and cofactors. Uridine, DHA, EPA, and choline are precursors for phospholipids, which are the main constituents of neuronal membranes. B-vitamins, vitamin C, vitamin E, selenium, and dietary phospholipids act as cofactors by increasing the availability of membrane precursors or by directly affecting the neuronal membrane or membrane synthesis. Combined administration of these nutritional precursors and cofactors is needed to stimulate membrane formation and function (green square). These changes have been shown to be accompanied by increases in neurite outgrowth, levels of specific pre- and post-synaptic proteins, and the number of dendritic spines (purple squares), all prerequisites for new synapse formation.

The synthesis of all major membrane phospholipids is dependent on circulating nutritional precursors. For example, the synthesis of PC may utilize choline, a pyrimidine (e.g., uridine), and PUFAs (e.g., DHA). These precursors act by enhancing the substratesaturation of the enzymes that catalyze the rate-limiting steps in phospholipid syntheses. All three precursors are required to augment the synthesis of $\mathrm{PC}$ in neuronal membranes. Because they must be obtained by the brain almost entirely from the circulation, blood levels of these precursors can markedly affect the overall rate of phospholipid synthesis [50].

Other nutrients act as cofactors in the synthesis of phospholipids, either by increasing the availability of phospholipid precursors (described in more detail below) or by directly affecting the Kennedy pathway. Specifically, selenium may further stimulate PC syn- thesis by increasing the activity of a key enzyme in the Kennedy pathway, CDP-choline:DAG cholinephosphotransferase [51].

In a series of preclinical studies, Wurtman and coworkers demonstrated that membrane phospholipid synthesis is synergistically increased by co-administration of uridine, DHA or EPA, and choline, the rate-limiting substrates of the Kennedy pathway. Increasing the availability of these phospholipid precursors increases the levels of key intermediates in the Kennedy pathway. Uridine has been shown to significantly elevate levels of the intermediates uridine triphosphate (UTP), CTP [52-54], and CDP-choline in pheochromocytoma cells (PC-12) [52], a frequently used cell model of neuronal differentiation. Incubation of rat striatal brain slices with uridine increased utilization of choline to form CDP- 


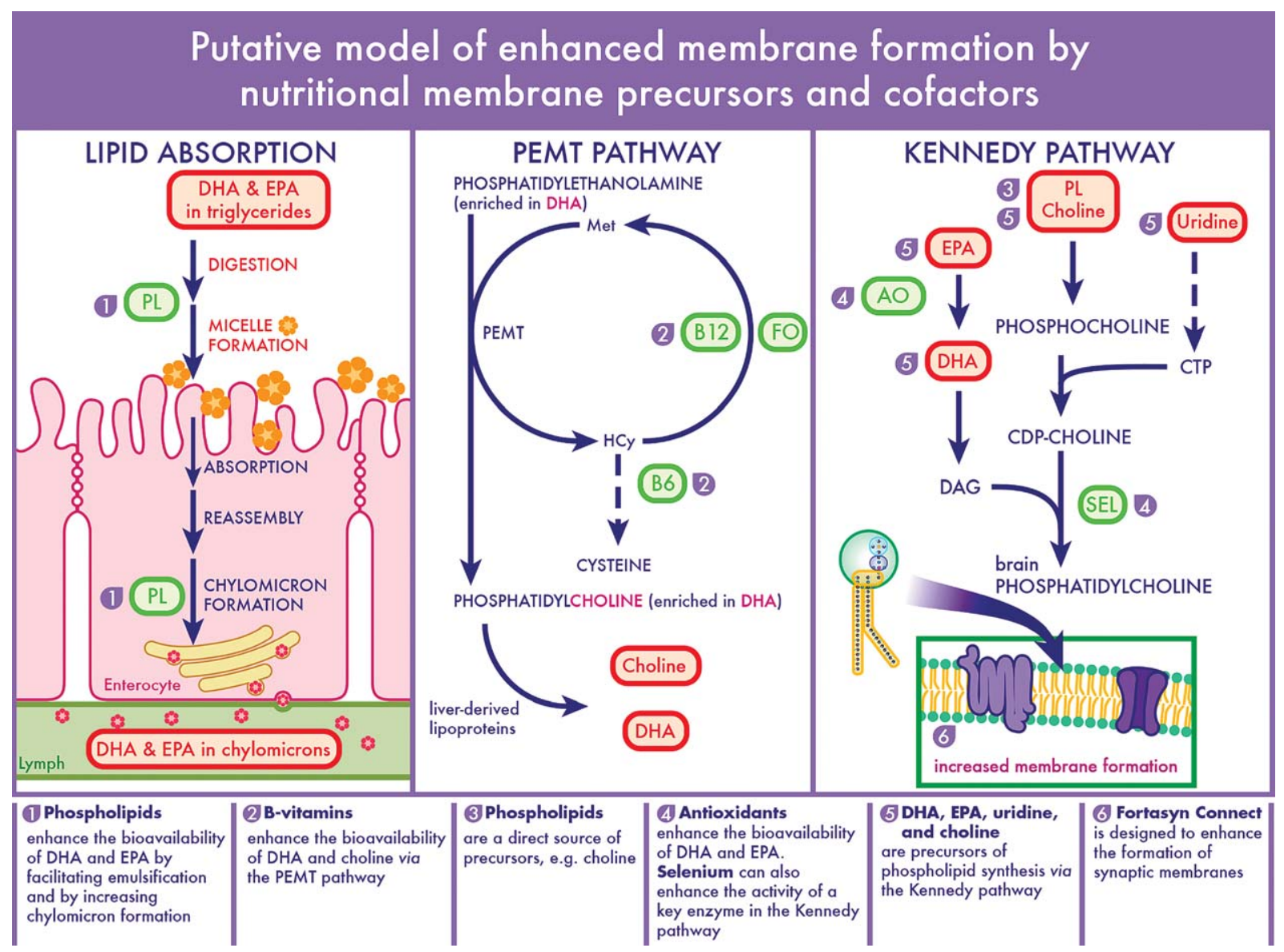

Fig. 2. The precursors and cofactors in Fortasyn Connect putatively act on several physiological and biochemical processes as depicted in the three panels. Increasing the formation of synaptic membranes requires a combined increased supply of nutritional membrane precursors and cofactors. Availability of membrane precursors (in red) is affected by their nutritional intake as well as by the intake of cofactors (in green) that increase precursor availability. Dietary phospholipids can increase the availability of the precursors DHA and EPA by increasing their absorption from the gut into the enterocytes and the lymph (left panel). Dietary folate, vitamin $\mathrm{B}_{12}$, and vitamin $\mathrm{B}_{6}$ intake influences plasma concentration of the precursors DHA and choline as their availability affects methylation capacity and plasma homocysteine levels, which in turn influences the PEMT pathway (middle panel). This especially is relevant in $\mathrm{AD}$, which is associated with high plasma homocysteine levels and B-vitamin deficiencies. Vitamin C, E, and selenium can serve as antioxidants to protect the membrane precursors DHA and EPA (right panel). The precursors for phospholipid synthesis (DHA, EPA, uridine, and choline), required for membrane formation, act by enhancing the substrate-saturation of the enzymes that catalyze the rate-limiting steps in the Kennedy pathway (right panel). Dietary phospholipids can also act as a direct source of precursors, whereas selenium may stimulate membrane synthesis by increasing the activity of a key enzyme in the Kennedy pathway (right panel). AO, antioxidants; CDP-choline, cytidine diphosphate choline; CTP, cytidine triphosphate; DAG, diacylglycerol; B6, vitamin $\mathrm{B}_{6}$; B12, vitamin $\mathrm{B}_{12}$; DHA, docosahexaenoic acid; EPA, eicosapentaenoic acid; FO, folate; HCy, homocysteine; Met, methionine; PEMT, phosphatidylethanolamine- $N$-methyltransferase; PL, dietary phospholipids; SEL, selenium.

choline [55]. Oral choline administration increased brain phosphocholine levels in rats [56], whereas administration of UMP (a source of uridine) increased brain UTP, CTP, and CDP-choline levels in gerbils [57]. A recent study in healthy humans indicated that short-term oral uridine administration increased brain levels of the intermediates phosphocholine and phosphoethanolamine [58].

Several in vitro and in vivo studies have shown that administration of the precursors that increase the levels of Kennedy pathway intermediates also raises brain phospholipid levels. In PC-12 cells, addition of DHA significantly stimulated the incorporation of ${ }^{14} \mathrm{C}$ choline into total cellular phospholipids [59]. Uridine supplementation to rat striatal brain slices stimulated phospholipid synthesis [55]. Supplementation of the omega-3-PUFA DHA ( $300 \mathrm{mg} / \mathrm{kg}$ by gavage) and/or uridine (as UMP, $0.5 \mathrm{~g} / 100 \mathrm{~g}$ diet) to gerbils and rats consuming standard choline-containing diets $(0.1 \mathrm{~g} / 100 \mathrm{~g}$ diet $)$ significantly increased levels of brain 
phospholipids, PC, PE, SM, PI, and PS, with combined administration inducing the largest effects [60-66]. For example, gerbils that received daily supplementation of UMP or DHA for 4 weeks showed a rise in brain PC of 13-22\% compared with control levels. Combined supplementation of UMP and DHA increased PC levels up to $45 \%$ of control levels. Similar results were obtained for the other brain phospholipids, in which combined supplementation increased phospholipid levels by 39-74\% [66]. These effects were observed irrespective of phospholipid levels being expressed per mg protein or per cell (DNA), indicating that each brain cell contained more membrane phospholipids. Similar to DHA, the omega-3 PUFA EPA induced an increase in brain phospholipid levels in gerbils [60]. The effect of EPA was amplified when supplemented in combination with UMP, as was also observed with DHA. EPA possibly acts as a precursor for brain DHA $[67,68]$. EPA is found only in trace amounts in brain phospholipids [50]; however, after transport to the brain EPA can be converted to DHA through elongation, desaturation, and oxidation steps. Thus, increased dietary intake of EPA could increase brain phospholipid synthesis via metabolism to DHA [60]. Unlike DHA and EPA, the omega-6 PUFA arachidonic acid administered orally to gerbils did not promote membrane synthesis $[60,65]$. The mechanisms that underlie the differential effects of DHA (and EPA) and arachidonic acid on phospholipid synthesis are not elucidated, but possibly involve differences in substrate specificity of enzymes that utilize omega-3 PUFAs and omega-6 PUFAs prior to and after their incorporation into phospholipids [60].

Other groups have also demonstrated the effects of nutritional precursors or combinations thereof on phospholipid synthesis. The membrane phospholipid content of PC-12 cells was shown to be increased by supplementing a combination of choline plus cytidine (which is a pyrimidine, like uridine) [69]. Increased membrane PS levels were found in neuroblastoma cells supplemented with DHA [70]. Shahdat et al. [71] demonstrated that DHA administered orally significantly increased rat brain phospholipid content. Dietary enrichment with a specific combination of membrane precursors and cofactors (DHA, EPA, uridine, choline, folate, vitamin $\mathrm{B}_{12}$, vitamin $\mathrm{B}_{6}$, phospholipids, vita$\min \mathrm{C}$, vitamin $\mathrm{E}$, and selenium, i.e., FC) also increased neuronal membrane PC levels in the intracerebroventricular (ICV) A $\beta$-infused rat model of AD [72].

The above-mentioned studies demonstrated that supplementation with uridine, DHA or EPA, and choline stimulates formation of neuronal membranes.
Since each precursor can become rate-limiting in elevating phospholipid synthesis, combined supplementation of these precursors induces a more pronounced effect on neuronal membrane synthesis than single nutrient supplementation.

\section{Increasing the availability of membrane precursors}

The availability of membrane precursors in the blood and the brain is largely dependent on their nutritional intake [50]. For example, supplementing humans with DHA [73], choline [74], or the combination of folic acid, vitamin $B_{12}$, and $B_{6}[75]$ result in increased levels in the circulation. Few data are available on the effects of oral intake of UMP on plasma levels of uridine in humans. In an experiment described by Cansev et al. [76], plasma concentration of uridine increased after acute oral intake of UMP. Recently, plasma uridine concentration was measured in healthy human subjects after oral intake of one serving of a medical food containing $625 \mathrm{mg}$ UMP/125 mL. The effect of this medical food was compared with an equimolar UMP solution in water and with a control product that lacked UMP. Mean baseline plasma uridine concentration of all healthy subjects was $6.4 \mu \mathrm{mol} / \mathrm{L}$. Plasma uridine concentrations were significantly and equally increased following oral intake of the UMP-containing medical food or the UMP solution. One hour after oral intake plasma uridine concentrations peaked at 14.6 $\mu \mathrm{mol} / \mathrm{L}$ (medical food) and $14.2 \mu \mathrm{mol} / \mathrm{L}$ (UMP solution), after which uridine concentrations gradually declined toward baseline concentrations in 4 hours. These data indicate that $625 \mathrm{mg}$ UMP either in the medical food or in a water solution is readily absorbed and increases plasma uridine levels up to $240 \%$ of basal levels, and that the effects of UMP on postprandial plasma uridine levels is unaffected by the solution matrix (Fig. 3; unpublished data).

Uridine, choline, and DHA are all known to readily enter the brain. Their transport into the brain involves simple diffusion or passive or active transport by specific membrane transport proteins located at the blood-brain barrier or the choroid plexus [50]. Not surprisingly, experimental data show that plasma levels of membrane precursors influence their levels in the brain. Administration of DHA [77-79], choline [80, 81], and uridine (as UMP) [57] have been shown to directly increase their levels in the brain. Conversely, lower circulating nutrient levels could limit their utilization by the brain, resulting in reduced neuronal membrane synthesis. 


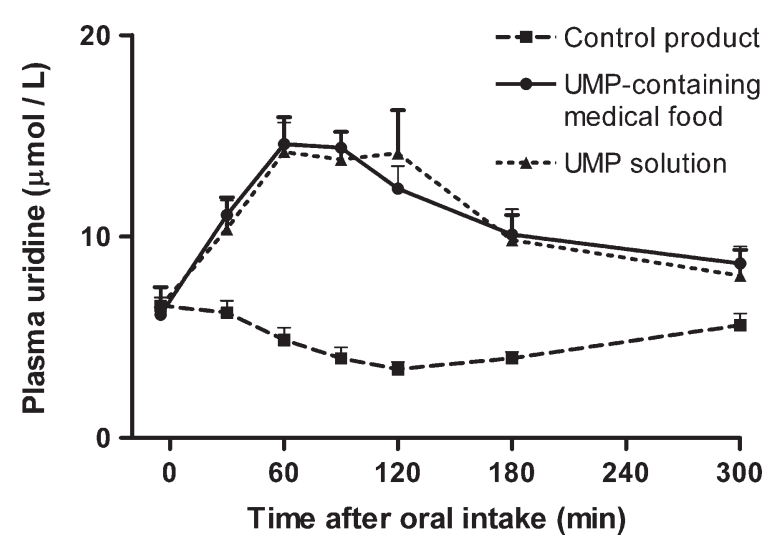

Fig. 3. The effects of acute oral intake of a UMP-containing medical food on plasma uridine concentration in humans. Healthy subjects received either one serving of the medical food $(625 \mathrm{mg}$ uridine monophosphate (UMP)/125 mL), an equimolar UMP solution in water $(625 \mathrm{mg} \mathrm{UMP} / 125 \mathrm{~mL})$, or a control product $(125 \mathrm{~mL})$ that was isocaloric and similar in flavor and appearance as the medical food but lacked UMP, DHA, EPA, choline, phospholipids, folic acid, vitamin $B_{12}$, vitamin $B_{6}$, vitamin $C$, vitamin $E$, and selenium. Baseline samples were taken 5 minutes prior to oral intake. Values are means, with their standard errors represented by vertical bars ( $n=5$ per experimental group). Plasma uridine levels increased after oral intake of either the UMP-containing medical food or the UMP solution but not after oral intake of the control product. Repeated measures ANOVA with Bonferroni post-test revealed a significantly increased postprandial uridine curve following intake of either the medical food ( $p=0.002)$ or the UMP solution $(p=0.002)$ compared with control. The medical food or the UMP solution did not induce significantly different postprandial curves, i.e., the postprandial uridine curve was unaffected by the solution matrix $(p=1.00)$. The UMP-containing medical food used in this experiment was Souvenaid.

The availability of membrane precursors is not only affected by their nutritional intake, but also by the intake of cofactors that influence precursor uptake, synthesis, degradation, or distribution in the body. The different physiological and biochemical processes involved and the putative role of the precursors and cofactors contained within FC are summarized in Fig. 2.

Folate, vitamin $\mathrm{B}_{12}$, and vitamin $\mathrm{B}_{6}$ are essential nutritional components in one-carbon metabolism and are required for methylation capacity. The availability of these vitamins may therefore modify the methylation of PE to PC by phosphatidylethanolamine$N$-methyltransferase (PEMT) in the liver. This has important implications for the metabolism of choline and DHA. By increasing PC synthesis, B-vitamin supplementation could not only increase endogenous choline synthesis, but also reduce choline utilization by the betaine-homocysteine methyltransferase (BHMT) pathway [82-85]. PC synthesis by PEMT can also influence the transport of PUFAs, like DHA, from the liver to the plasma and other tissues [86-88]. Recent experiments in rats have confirmed these hypotheses by demonstrating that combined dietary folic acid, vitamin $\mathrm{B}_{12}$, and vitamin $\mathrm{B}_{6}$ supplementation increases concentrations of plasma choline [89] and DHA [90]. In this way, intake of supplemental B-vitamins may increase the availability of choline and DHA (Fig. 2, middle panel). Conversely, B-vitamin deficiencies and concurrent high plasma homocysteine levels, as commonly observed in AD [91], may impair the transport of DHA from the liver, decrease the synthesis of choline, and increase the utilization of choline. It can therefore be expected that combined intake of B-vitamins, DHA, and choline by individuals with a low B-vitamin status and/or high plasma homocysteine level, would be more effective in increasing DHA and choline availability than intake of DHA and choline alone.

Dietary phospholipids can increase precursor availability by two distinct mechanisms. First, phospholipids act as a direct source of precursors. Dietary phospholipids are digested into fatty acids, lysophospholipids, phosphatidic acid, glycerol, monoglycerides, and other compounds, including choline and ethanolamine. These digestion products are subsequently absorbed and either further metabolized or directly used as precursors for neuronal membrane synthesis (Fig. 2, right panel). For example, the intake of phospholipids has been shown to increase levels of choline in human plasma [74] and the rat brain [92]. Second, phospholipids could act as a cofactor by enhancing the absorption of DHA and EPA from the gut. Dietary supplementation of phospholipids that did not contain any DHA increased the concentration of DHA in plasma of rats fed a DHA-containing diet [93]. The effects of phospholipid supplementation on the availability of DHA levels might be explained by an improved absorption of DHA from the gut, since dietary phospholipids are known to facilitate the emulsification of dietary fat in the lumen [94]. Moreover, dietary phospholipids may increase the intestinal uptake of fat by increasing the formation of chylomicrons in enterocytes and subsequent secretion into the lymph [95, 96] (Fig. 2, left panel).

Together, these data show that the availability of membrane precursors is affected by their nutritional intake as well as by the intake of cofactors that influence precursor uptake and metabolism. Consequently, addition of nutritional cofactors potentially facilitates the synthesis of membrane phospholipids by enhancing the availability of the rate-limiting precursors. 
Modulation of neuronal membrane structure and function by specific nutritional compounds

Biochemical and biophysical properties of the neuronal membrane are important determinants of normal functioning of membrane-dependent processes contributing to neuronal functioning. Figure 4 displays a schematic representation of these membrane properties, including fatty acid and phospholipid composition, cholesterol level, sphingolipid level, lateral and rotational fluidity, membrane asymmetry, membrane thickness, and composition of distinct lateral membrane domains called lipid rafts. Membrane fluidity generally refers to the viscosity and stiffness of the membrane bilayer which is highly dependent on the fatty acid composition of the phospholipids. Lipid rafts are membrane microdomains with high levels of cholesterol, sphingolipids, and saturated fatty acids and a reduced level of PUFAs. Alteration of such biochemical and biophysical properties can markedly affect a multitude of membrane-dependent processes, including structure, function, and activity of receptors, ion channel activation, axonal neurotransmission, activity of membrane-bound enzymes, cell signaling, optimal exchange of nutrients and other molecules, and mitochondrial membrane function [42-44, 97, 98]. Membrane lipids serve as sources of several intermediates of signal transduction pathways, including those associated with cell growth, differentiation, oxidative stress, inflammation, and apoptosis [99, 100].

Neuronal membrane structure and function are subject to alterations induced by nutritional compounds. Dietary supplementation with omega-3 PUFAs has repeatedly been shown to affect cell membrane composition, thereby influencing its biophysical properties. Supplementation of cell culture media with DHA significantly increased membrane omega-3 PUFA levels in $A \beta$ protein precursor (A $\beta P P)$-transfected Chinese hamster ovary (CHO) cells [101]. Membrane omega3 PUFA levels were also increased in brains of rats following oral supplementation with DHA [71, 102], dietary supplementation with DHA-containing phospholipids [103], or a multi-nutrient intervention including omega-3 PUFAs [104]. In line with these results, dietary supplementation of FC to rats and mice has been shown to increase membrane omega-3 PUFAs levels in the brain [72, 105]. A high level of omega3 PUFAs in neuronal membranes is associated with increased membrane fluidity and changed composition of lipid rafts, with favorable effects on numerous membrane-dependent processes [28, 42], including those that play a role in $\mathrm{A} \beta$-related pathology.
Neuronal membranes are susceptible to the damaging effects of oxidative stress. Oxidative stress can cause lipid peroxidation and alter membrane composition, two processes particularly evident in AD [106]. Extensive lipid peroxidation in biological membranes causes loss of fluidity, reductions in membrane potential, increased ionic permeability, and eventually cell death [107]. Vitamin C (ascorbic acid), vitamin E ( $\alpha$-tocopherol), and selenium (as part of the enzyme glutathione peroxidase) serve as antioxidants to protect both the lipid precursors (i.e., DHA and EPA) and the resulting membrane components from lipid peroxidation [107]. In addition, these nutrients are known to affect neuronal membranes: vitamin $\mathrm{C}$ contributes to optimal collagen synthesis [108], required for neurite outgrowth and synapse formation [109]; selenium is part of selenoprotein $\mathrm{P}$, which is required for normal synaptic functioning [110]; and vitamin $\mathrm{E}$ is a structural component of neuronal membranes [111], primarily associated with PC molecules [112] and concentrated at neurite junctions [113].

These observations imply that specific nutrients (e.g., omega-3 PUFAs, vitamin C, vitamin E, and selenium) can improve the structure and function of neuronal membrane and therefore may improve membrane-dependent processes.

In summary, stimulating the formation and function of neuronal membranes requires a combined increased supply of membrane precursors and cofactors. Availability of membrane precursors is affected by their nutritional intake as well as by the intake of cofactors that increase precursor availability. Besides increasing the availability of phospholipid precursors, cofactors may directly affect the neuronal membrane or membrane synthesis.

\section{COMBINED ADMINISTRATION OF MEMBRANE PRECURSORS AND COFACTORS MODULATES SYNAPSE FORMATION, NEUROTRANSMISSION, AND A $\beta$-RELATED PATHOLOGY}

Increasing the availability of membrane precursors and cofactors hypothetically improves processes relevant in $\mathrm{AD}$ that are partly or largely dependent on membrane formation and function: synapse formation, neurotransmission, $A \beta$-related pathology, and ultimately cognitive performance. The data summarized below indicate that these processes are affected by combined administration of membrane precursors and cofactors. Figure 5 represents a schematic overview 
Schematic representation of biochemical and biophysical properties of neuronal membranes that influence membrane-dependent processes, e.g. receptor and enzyme activity

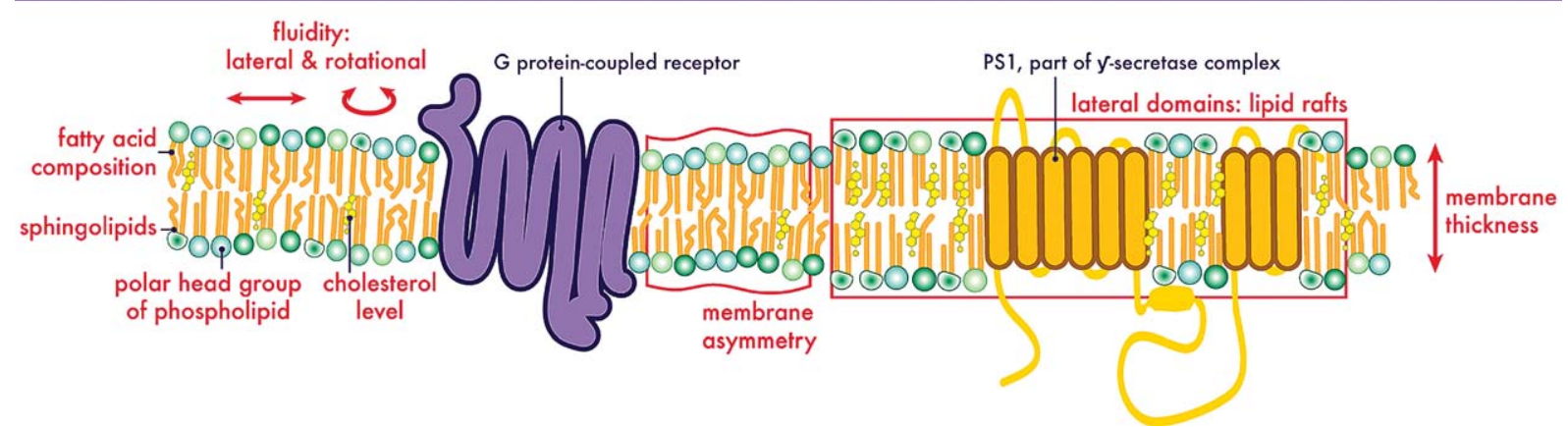

Fig. 4. The neuronal membrane is the principle site of action for many neuronal activities, e.g., G protein-coupled receptor activation and activity of $\gamma$-secretase. The active $\gamma$-secretase complex encompasses several proteins, of which presenilin (PS1 or PS2) is responsible for the cleavage of A $\beta P P$. Alteration of biochemical and physical alterations that directly influence the composition and structure of membranes can affect a multitude of membrane-dependent processes. These biochemical and biophysical properties of the neuronal membrane are, therefore, important determinants of proper neuronal function. In red, several of these membrane properties are indicated: fatty acid and phospholipid composition, cholesterol level, sphingolipid level, lateral and rotational fluidity, membrane asymmetry, membrane thickness, and the composition of lipid rafts. These properties have been shown to be subject to alterations induced by nutritional compounds.

of the putative mechanisms of action of the specific combination of nutrients present in FC.

\section{Stimulating synapse formation}

Synaptic communication takes place at the junctions between a terminal button of a pre-synaptic neuron and specific membrane structures of a post-synaptic neuron, e.g., dendritic spines. Synapses consist principally of neuronal membranes that are composed of phospholipids and which are associated with specific pre- and post-synaptic proteins. Synapse formation and elimination occurs throughout life [114] and individual brain synapses are presently understood to be continuously remodeled in the adult brain [115]. Theoretically, the formation of new synapses requires the synthesis of new synaptic membrane and specific synaptic proteins. As summarized below, in vitro and in vivo studies have demonstrated that combined oral supplementation of the phospholipid precursors DHA or EPA, uridine or UMP, and choline not only increases the synthesis of phospholipids, but also increases neurite outgrowth, levels of specific pre- or post-synaptic proteins, and the number of dendritic spines, all indicative for new synapse formation. Several previously published reviews on this subject provide extensive summaries [50, 116, 117].

In nerve growth factor-stimulated PC-12 cells, uridine supplementation increases neurite outgrowth and neurite branching in a dose-dependent manner, possibly via increased PC synthesis [53]. In the same cell line, choline plus cytidine supplementation significantly increased neurite outgrowth [69]. DHA supplementation increased neurite outgrowth and neurite branching in embryonic hippocampal cultures from rats [118] and mice [119], and in neuronal cultures derived from mouse embryonic stem cells [120]. A combination of omega-3 PUFAs and multiple vitamins and minerals was more effective in promoting neurite outgrowth in neuroblastoma cells (measured as average neurite length and the number of neurites per cell) compared with either omega-3 PUFAs or vitamins plus minerals alone [121]. Enrichment of cell culture medium with a combination of vitamins $\mathrm{B}_{1}$, $\mathrm{B}_{6}$, and $\mathrm{B}_{12}$ increased neurite outgrowth from dorsal root ganglia [122]. The levels of neurofilament-70 and neurofilament-M proteins, two markers of neurite outgrowth, were increased after supplementation of uridine in PC-12 cells [53], and after oral supplementation of UMP [123] or DHA plus UMP [66] in rodents. In addition, He et al. [120] demonstrated that transgenic fat-1 mice (i.e., with intrinsic high levels of brain DHA) show significantly enhanced hippocampal neurogenesis, illustrated by an increased number of proliferating hippocampal neurons.

Supplementation of (combinations of) phospholipid precursors also increases the levels of proteins that are associated with pre- and post-synaptic membranes. In a study by Cao et al. [119], DHA supplementation increased expression of the pre-synaptic vesicular protein synapsin-1 in mouse embryonic hippocampal cultures, whereas omega-3 PUFA deprivation caused 
Putative effects of a specific nutrient combination on membrane-related pathology in AD

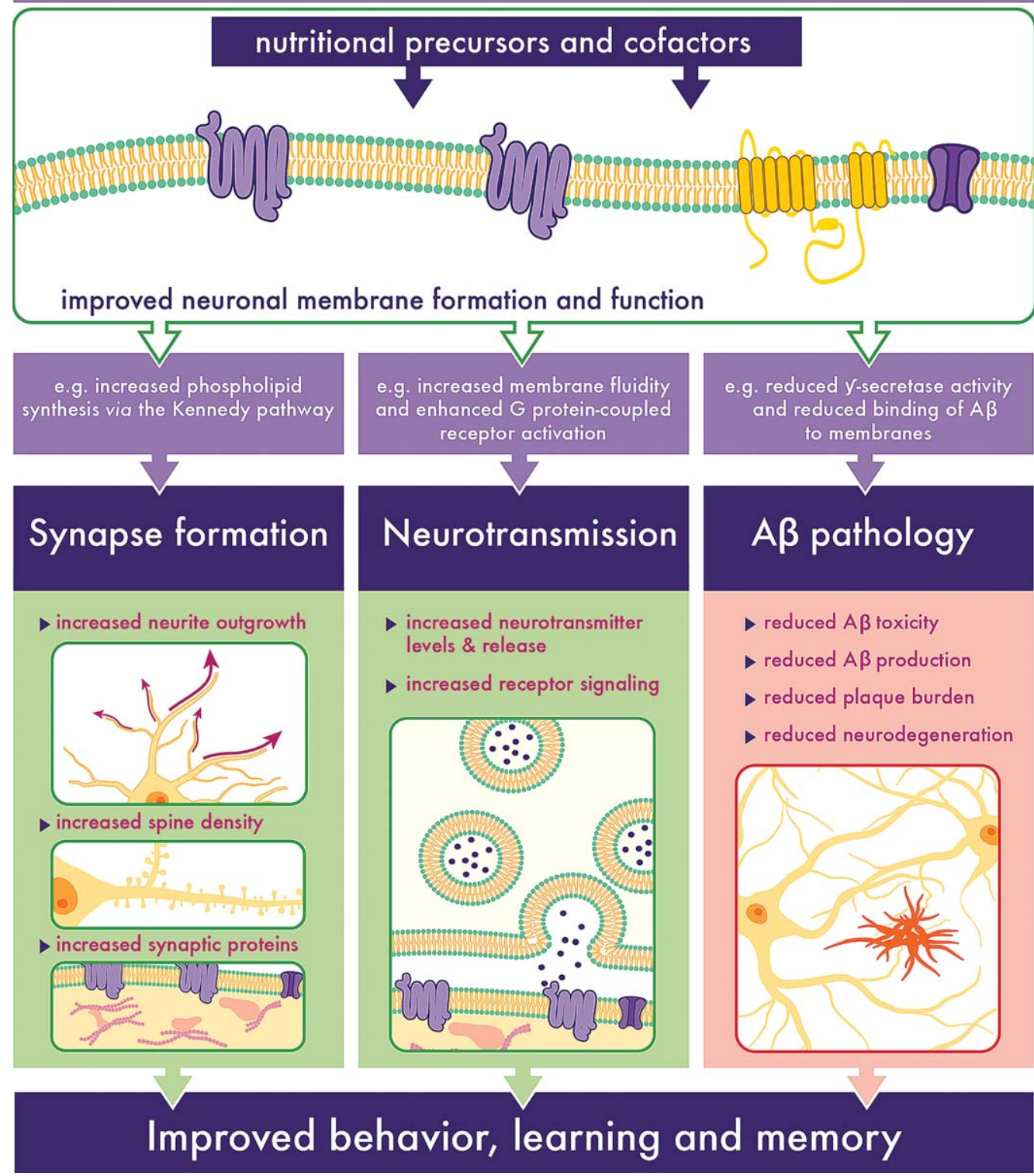

Fig. 5. Increasing the availability of the nutritional precursors and cofactors, provided by Fortasyn Connect, stimulates membrane formation and function. In this way, this specific nutrient combination improves membrane-dependent processes that are of potential relevance for patients with AD. The membrane precursors and cofactors act in concert to increase the synthesis of membrane phospholipids via the Kennedy pathway and to increase neurite outgrowth, levels of specific pre- or post-synaptic proteins, and the number of dendritic spines, all prerequisites for new synapse formation (left panel). Neurotransmission is also increased by co-administration of membrane precursors and cofactors, not only via increased neurotransmitter levels and release, but also via increased receptor signaling, e.g., by an enhanced $\mathrm{G}$ protein-coupled receptor activation (middle panel). By improving neuronal membrane structure and function, membrane precursors and cofactors reduce both $\mathrm{A} \beta$ production and toxicity resulting in decreased plaque formation and reduced neurodegeneration. These changes ultimately may lead to an improved learning and memory performance.

a decrease in synapsin-1 expression in hippocampi of young mice. The loss of the post-synaptic proteins drebrin (actin-regulating dendritic spine protein) and post-synaptic density 95 (PSD-95), the increased cleavage of the cytoskeleton protein actin, and the resulting dendritic pathology induced in transgenic AD mice (Tg2576) when fed an omega-3 PUFA deficient diet, were prevented by dietary DHA enrichment 
[124]. DHA and/or UMP supplementation to gerbils and rats fed standard choline-containing diet increased levels of several synaptic proteins, including PSD-95, synapsin-1, and syntaxin-3 [60-62, 65, 66]. The combined supplementation of DHA and UMP resulted in the largest effects on synaptic protein levels. These increases in pre- and post-synaptic protein levels indicate that the administration of phospholipid precursors in particular raises levels of membranes associated with synapses.

New synapses can form when a dendritic spine interacts with a pre-synaptic terminal button [125]. Since dendritic spine growth precedes synapse formation, and new synapses form preferentially onto existing buttons [126], the rate of synaptogenesis depends in part on the numbers of dendritic spines that are being formed. He et al. [120] demonstrated that high levels of brain DHA in transgenic fat- 1 mice increased the hippocampal expression of synaptic proteins (e.g., PSD-95 and synapsin-1) and increased dendritic spines density of hippocampal pyramidal neurons. The effects of oral supplementation of DHA and/or UMP on dendritic spine number (in CA1 pyramidal hippocampal neurons) were examined in adult gerbils receiving standard choline-containing diets [65]. DHA supplementation (without UMP) caused dose-related increases in spine density (by 19\% of control levels) in parallel with increases in membrane phospholipids and in specific pre- and post-synaptic proteins. This effect was almost doubled (up to $36 \%$ of control levels) if animals also received UMP. In contrast to these findings, oral supplementation with the omega-6 PUFA arachidonic acid had no effect on spine density in the adult gerbil hippocampus, indicating specificity of omega-3 PUFAs [65]. Similar studies were performed in pregnant rats and their offspring [61]. Brains of weanlings exhibited significant increases in hippocampal dendritic spine density; the largest effect was observed with the combined supplementation of DHA and UMP.

These observations suggest that DHA (and EPA), uridine, and choline act together to increase the synthesis of synaptic membranes and, consequently, synaptogenesis. Such an effect would be beneficial in situations with increased synapse loss leading to functional decline, like in $\mathrm{AD}$.

\section{Enhancing neurotransmission}

Neurotransmission is a process in which neurotransmitters are released from the pre-synaptic terminal button into the synaptic cleft and have an excitatory or inhibitory effect on receptors of the post-synaptic membrane of, for example, a dendritic spine. Improving synaptic functioning or increasing the formation of synapses is expected to enhance synaptic neurotransmission. As described in detail below, several experiments have shown that membrane precursors and cofactors affect neurotransmitter levels and release, as well as receptor levels and functioning.

In experiments by Aid et al. [127, 128], dietary enrichment with omega-3 PUFAs (including DHA) or DHA-containing phospholipids normalized omega3 PUFA deficiency-induced changes in hippocampal basal and stimulated acetylcholine (ACh) release; this was ascribed to changes observed in membrane composition. Furthermore, dietary DHA-containing phospholipids have been demonstrated to restore aging-induced reductions in hippocampal basal and stimulated ACh release [103]. Wang et al. [129] showed that the consumption of a diet containing UMP and standard levels of choline by young and aged rats led to increased striatal ACh levels and increased basal and stimulated release of $\mathrm{ACh}$, which was paralleled by an increase in striatal PC, PE, and PS levels. Striatal dopamine levels and stimulated release of dopamine were found to be increased in aged rats following consumption of UMP [123]. The increase in neurotransmitter content and release might be ascribed to a UMP-induced increase in neuronal membrane formation, and hence synapse formation and/or increased synaptic vesicle formation. In addition, by increasing PC, UMP might indirectly increase choline availability for the synthesis of ACh, since choline can be made available from PC in neuronal membranes [130]. Rats fed choline enriched diets also show increased brain ACh levels [80] and increased cortical release of ACh [131], in which choline probably acts as a direct precursor for ACh synthesis in the brain. In an experiment by Cansev et al. [62], oral supplementation with UMP, DHA, or the combination of UMP and DHA, partially restored dopaminergic neurotransmission in rats with unilateral 6-hydroxydopamine striatal lesions. Striatal dopamine content in both the intact and lesioned striatum was increased, and the combination of UMP plus DHA was more effective than supplementation of either nutrient alone. UMP and DHA were hypothesized to ameliorate the impairment in dopaminergic transmission by increasing the amount of synaptic membrane, as increased brain phospholipid levels and synaptic protein levels were also observed in these animals.

Administration of nutrients that improve membrane structure and function can also influence receptor 
signaling. The combination of DHA, EPA, uridine, choline, folate, vitamin $\mathrm{B}_{12}$, vitamin $\mathrm{B}_{6}$, phospholipids, vitamin $\mathrm{C}$, vitamin $\mathrm{E}$, and selenium (i.e., FC) has been demonstrated to synergistically enhance muscarinic M1 G protein-coupled receptor activation in vitro [132]. Muscarinic receptor activation is relevant for $\mathrm{AD}$ as both muscarinic and nicotinic $\mathrm{ACh}$ receptor abnormalities are known to be involved in the pathology of AD [133]. Addition of single nutrients to the cell culture medium had little effect on muscarinic M1 receptor response. Combining DHA, uridine, and choline resulted in an increased receptor response and the subsequent additions of B-vitamins, antioxidants, and PUFAs further increased the response. The largest receptor response was observed with the full combination of membrane precursors and cofactors contained within FC, indicating a concerted action of these nutrients on membrane-dependent processes [132]. In vivo studies have also demonstrated effects of dietary intake of specific nutrients, or combinations thereof, on receptor levels and/or binding. Dietary omega-3 PUFA deficiency has previously been shown to decrease muscarinic receptor binding in rat hippocampi [128], to decrease levels of the $\alpha$-amino-3hydroxy-5-methylisoxazole (AMPA) receptor subunit GluR-1 and the N-methyl-D-aspartate (NMDA) receptor subunits, NR1, NR2a, and NR2b, in hippocampi of young mice [119], and to decrease levels of NR2a and NR2b in the cortices and hippocampi of aged transgenic mice (Tg2576) [134]. The latter effect was reversed by dietary DHA enrichment [134]. Feeding rats a diet enriched with a combination of omega-3 PUFAs, B-vitamins, and antioxidants enhanced hippocampal muscarinic M1 receptor binding, whereas a diet additionally enriched with choline, phospholipids, and other nutrients increased binding to both muscarinic M1 and serotonergic 1A receptors [135]. Sakamoto et al. [65] demonstrated significantly elevated expression of GluR-1 in gerbil hippocampi after treatment with DHA alone, and to a greater extent with combined oral supplementation of DHA and UMP.

\section{Reducing A $\beta$ production and toxicity}

Soluble $A \beta$ oligomers have been proposed as the neurotoxic pathogenic agents inducing the loss of dendritic spines and synapses in AD [4, 8, 9, 136-138]. It has been suggested that the neurotoxic cascade of $\mathrm{A} \beta$ leading to synapse loss and synaptic dysfunction may be initiated at neuronal cell membranes and that soluble $\mathrm{A} \beta$ oligomers disturb neuronal membrane properties by binding to membrane components [139,
140]. The composition of neuronal membranes may in turn influence the membrane-disrupting properties of $\mathrm{A} \beta$ and therefore its toxicity [141]. Moreover, membrane structure and function have been documented to exert a direct impact on $\mathrm{A} \beta \mathrm{PP}$ processing and the production of $\mathrm{A} \beta[139,142]$. This is comprehensible as all A $\beta P P$ processing enzymes as well as A $\beta P P$ itself are integral membrane proteins. For example, $\beta$ - and $\gamma$-secretase activity is influenced by the composition of lipid rafts in which these enzymes are concentrated [143, 144] and membrane bilayer thickness has been shown to directly affect the activity and cleavage specificity of $\gamma$-secretase [145]. Thus, it can be hypothesized that specific nutritional compounds which improve neuronal membrane composition, structure, and function reduce both $\mathrm{A} \beta$ toxicity and $\mathrm{A} \beta$ production.

Supplementation with nutritional membrane precursors and cofactors has been demonstrated to be effective in reducing $A \beta$ production and toxicity in several in vitro models. Grimm et al. [143] investigated the effect of increasing the neuronal membrane DHA content on amyloidogenic and non-amyloidogenic A $\beta P P$ processing in A $\beta P P$-transfected and non-transfected neuroblastoma cell lines and purified membranes from mouse brain. They demonstrated that supplementation of DHA directs the processing of A $\beta P P$ toward the non-amyloidogenic pathway, effectively reducing $A \beta$ production by directly decreasing the activity of $\beta$ and $\gamma$-secretase and increasing the protein stability of $\alpha$-secretase. In line with these findings, incubation of

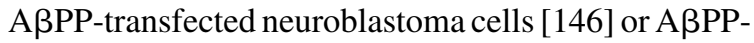
transfected CHO cells [101] with DHA effectively reduced $A \beta$ levels. In an experiment by Oksman et al. [147], DHA supplementation of a neuroblastoma cell culture was shown to reduce $A \beta$ production in a dose-dependent manner. DHA or EPA incubation protected rat embryonic cortical neurons and neuroblastoma cells from the toxic effects of soluble $A \beta$ oligomers [148]. It was suggested that DHA enrichment had induced changes in neuronal membrane properties, thereby increasing protection against $A \beta$ toxicity. In Cos-7 SP-C99-transfected cells (expressing the C-terminal fragment of A $\beta P P, A \beta P P-C 99)$ supplemented with different phospholipids, modulation of $A \beta$ production was depended on the composition of phospholipids in the membrane bilayer, influencing intra-membranous proteolysis of A $\beta P P$ [149]. A combination of choline plus cytidine significantly reduced amyloidogenic processing of A $\beta P P$ in PC-12 cells, possibly by the concurrently observed effects on membrane PC levels [69]. 
The potential protective effects of nutritional components have also been investigated in transgenic mouse models of AD (AßPP/PS1; Tg2576; 3xTg$\mathrm{AD}$; TgCRND8). Deficiency of folate, vitamin $\mathrm{B}_{12}$, and vitamin $\mathrm{B}_{6}$ has been associated with significant increases in $A \beta$ deposition $[150,151]$, whereas transgenic mice supplemented with vitamin $\mathrm{E}$ showed reduced levels of $A \beta[152,153]$. Dietary supplementation with omega-3 PUFAs in transgenic mouse models of $\mathrm{AD}$ reduced $\mathrm{A} \beta$ levels [147, 154, 155], reduced plaque load $[154,156]$, lowered vascular $A \beta$ deposition [156, 157], altered A $\beta P P$ processing [154], and reduced levels of presenilin 1 (PS1, part of the $\gamma$ secretase complex) [155]. In vivo $\beta$ - and $\gamma$-secretase activities have also been shown to be significantly decreased in normal $\mathrm{C} 57 \mathrm{Bl} / 6 \mathrm{~J}$ mice fed an omega3 PUFA enriched diet compared with mice fed a control diet [143]. Although the effects of omega-3 PUFAs (including DHA) on $\mathrm{A} \beta$ production and levels in vivo seem robust, several studies do not show consistent effects on every parameter measured. For instance, Oksman et al. [147] found effects on soluble and insoluble $A \beta$ levels, but no effects on $A \beta$ plaque load. Moreover, in other studies using transgenic mouse models of $\mathrm{AD}$, no effects of dietary omega-3 PUFAs on A $\beta$ levels were observed [158, 159]. The inconsistent results might be due to differences in study design, although other studies suggest that the effectiveness of nutritional supplementation on $A \beta$ pathology depends on the combined availability of specific nutrients. A $\beta P P / P S 1$ transgenic mice fed an FC-enriched diet had decreased total brain $A \beta_{42}$ levels, $A \beta_{40}$ levels, and reduced amyloid plaque burden in the hippocampus [105]. These mice showed reduced plaque-associated neurodegeneration in the brain, indicating that dietary enrichment with this combination reduces $\mathrm{AD}$-like pathology. In contrast, in the same study, these protective effects were not observed in mice fed a diet enriched in DHA or DHA plus UMP, showing that other nutrients in FC contributed significantly to the overall effect of this diet. Furthermore, supplementation with this nutrient combination protected cholinergic neurons from $A \beta$-induced toxicity, as evidenced by preserved immunoreactivity for the membrane-bound enzymes choline acetyltransferase (ChAT) and vesicular ACh transporter (VAChT) following ICV infusion of $A \beta$ in rats [72]. It was speculated that the protective effects of the diet are mediated by the improved integrity of the neuronal membranes, thereby limiting the membrane binding and membrane-disrupting properties of $A \beta$ [72].
Thus, improving neuronal membrane structure and function by co-administering membrane precursors and cofactors potentially reduces both $A \beta$ production (by reducing amyloidogenic $A \beta P P$ processing) and $A \beta$ toxicity (by limiting the membrane-disrupting properties of $A \beta$ ) resulting in decreased plaque formation and reduced neurodegeneration. Hypothetically, this in turn diminishes the neurotoxic cascade of $A \beta$ that leads to synapse loss and synaptic dysfunction.

\section{MEMBRANE PRECURSORS AND COFACTORS IMPROVE MEMORY AND COGNITION IN RODENT MODELS}

Since supplementation with membrane precursors and cofactors can stimulate synapse formation, enhance neurotransmission, and decrease $A \beta$-related pathology, it was hypothesized that these nutrients would have significant effects on memory and other cognitive processes. Studies in various animal species and models support this hypothesis.

An improvement in behavior with dietary supplementation of omega-3 PUFAs, DHA, or EPA has been observed in healthy rodents [160] and models of cognitive dysfunction, including those specific for $\mathrm{AD}[68$, $124,147,156,159,161-163]$, although this is not consistently observed [158]. These effects can be augmented by co-administration of specific nutrients as pointed out in several experiment. Dietary UMP supplementation ameliorated memory deficits associated with rearing rats under impoverished conditions [164]. Using the same model, Holguin et al. [63] found that the combination of UMP and DHA was more effective at reducing the memory deficits in these rats as compared to supplementation of UMP or DHA alone. This effect may be mediated through the concurrently observed enhancement of synaptic membrane synthesis, as the authors suggested. In addition, oral UMP and/or DHA supplementation was also shown, in normal gerbils, to enhance learning and memory, with concomitant increased brain phospholipid levels. The largest effects on learning and memory again occurred when DHA and UMP were supplemented in combination [64]. Intake of DHA, PC, or their combination also enhanced learning ability and brain function in aged mice [165]. Spontaneously hypertensive rats exhibit deficiencies in selective attention and spatial learning, which were improved following dietary supplementation with UMP and choline [166]. In a rat model of chronic cerebral hypo-perfusion, a diet enriched with omega-3 PUFAs, choline, B-vitamins, phospholipids, 
and antioxidants restored hypo-perfusion-induced spatial learning and memory impairment [167]. The same nutritional combination also improved spatial learning and memory in normal rats [104]. Moreover, in both experiments, a diet with fewer additives (e.g., lacking supplemented choline and phospholipids) was less effective [104, 167], suggesting that supplementation with the indicated combination of nutrients was necessary to induce the largest effects on performance. In rats pre-infused with $A \beta$, dietary enrichment with FC prevented the $A \beta$-induced reduction in exploratory activity [72]. Supplementation of this nutrient combination to the diet of aged A $\beta P P / P S 1$ transgenic mice improved spatial learning and memory [168]. Dietary enrichment with FC also normalized reduced exploration of odor of conspecifics and impaired spatial learning in A $\beta P P / P S 1$ transgenic mice [169]. In this study, FC was more effective than omega-3 PUFA alone, indicating that the effects of DHA on cognition in A $\beta P P / P S 1$ mice can be further supported by the addition of other membrane precursors and cofactors.

Taken together, the effects of membrane precursors and cofactors on improving cognitive performance have been shown in various animal models. Although administration of single nutrients may already be effective, combined intake of these nutrients is required in order to reach a higher efficacy. Administration of membrane precursors and cofactors can increase cognitive performance probably by their effects on synapse function and formation, neurotransmission, and in ADspecific models also by reducing $\mathrm{A} \beta$-related pathology. More preclinical studies on the effects of FC on memory and cognition are currently ongoing within the framework of the LipiDiDiet project.

\section{CLINICAL UTILITY OF THE SPECIFIC NUTRIENT COMBINATION IN AD}

The experimental studies on FC in the previous sections indicate that this nutrient combination has potential clinical utility in AD. A nutritional product intended to manage a specific disease like AD via dietary intervention is commonly referred to as a medical food. A medical food is a food formulated for enteral intake by patients, taken under physician supervision, and intended to meet the specific nutritional requirements identified for a disease or condition, which cannot be met by modification of the normal diet. Several factors proposed to contribute to a disease-specific nutritional requirement in $\mathrm{AD}$, including: 1) alterations in nutrient intake, 2) com- promised nutrient absorption from the gut and uptake into the brain and reduced endogenous biosynthesis of nutritional compounds, and 3) an increased utilization of specific nutrients for neuronal membrane and synapse formation to compensate for the increased loss of synapses [170]. The diet of AD patients is not expected to provide the levels to meet these nutritional requirements. In fact, a recent systematic review and meta-analysis indicated that, in comparison with agematched cognitively intact individuals, AD patients have lower plasma levels of several nutrients, including vitamins $\mathrm{C}$, vitamin $\mathrm{E}$, folate, vitamin $\mathrm{B} 12$, and omega3 PUFAs [171]. Thus, while AD patients may have disease-specific nutritional requirements that are associated with pathological processes, many have lower circulating levels of these nutrients. To address these putative disease-specific nutritional requirements, the medical food Souvenaid, containing Fortasyn Connect, was designed to target synaptic dysfunction in early AD.

In early $\mathrm{AD}$, memory dysfunction is a key manifestation and is associated with increased loss of synapses [4, 10, 14]. Reducing synapse loss and improving synaptic function may preserve or improve neuronal communication and thereby positively affect memory and other cognitive functions. A clinical study program that covers a broad part of the AD spectrum is investigating the effects of the aforementioned medical food on memory and cognitive performance and the underlying hypothesis of ameliorated synaptic loss and dysfunction. In an initial randomized, double-blind, controlled proof of concept study of 225 drug-naïve patients with mild AD (Souvenir I), the medical food $(125 \mathrm{~mL} / 4 \mathrm{fl} \mathrm{oz})$ taken once daily for 12 weeks significantly improved memory using the Wechsler Memory Scale-revised delayed verbal recall task as the primary outcome measure (Fig. 6A) [172]. In patients with a more advanced stage of $\mathrm{AD}$ receiving standard $\mathrm{AD}$ medication, no effect of the intervention on cognition was observed (S-Connect study) [173], which suggest that this medical food offers the greatest potential when applied to earlier stages of AD. The Souvenir II study recently confirmed the efficacy of the medical food on memory in drug-naïve patients with mild $\mathrm{AD}$, and also extended the result through a longer intervention period of 24 weeks and through utilization of the whole memory domain z-score of a Neuropsychological Test Battery as the primary endpoint (Fig. 6B) [174]. EEG measures in this study served as secondary outcomes to investigate the biological effect on synaptic function. The EEG signal reflects synchronous activity of many synapses and is therefore a derivative of under- 

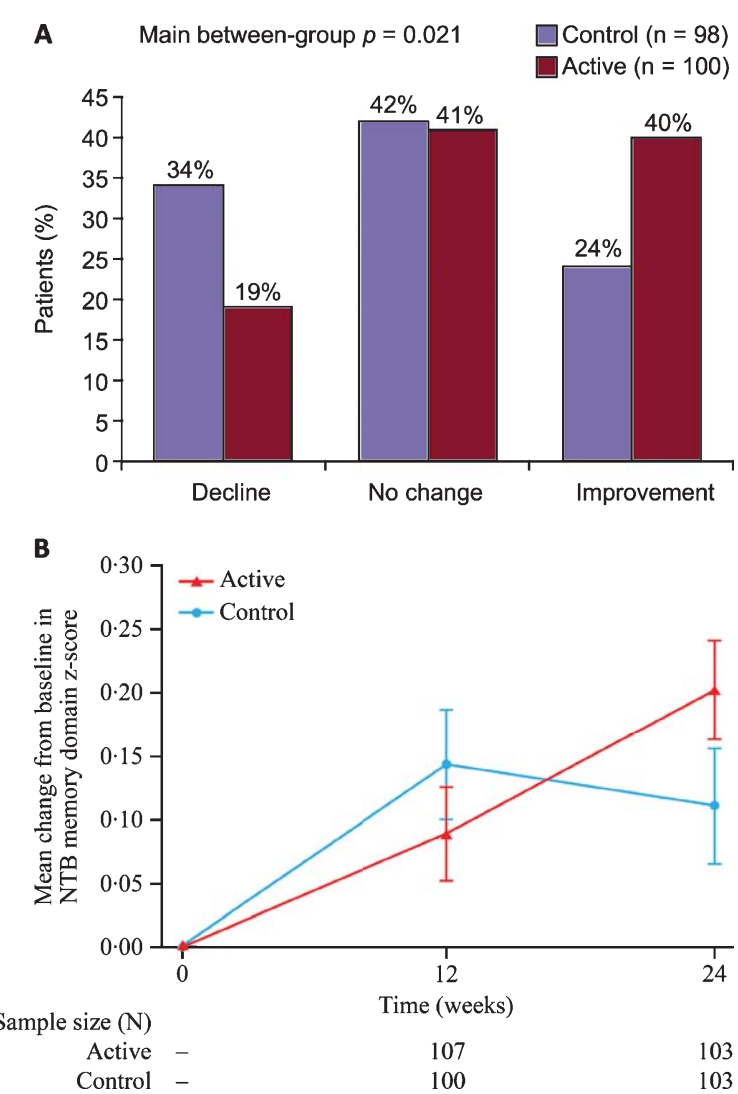

Fig. 6. Primary endpoints of two human intervention studies with the medical food Souvenaid, containing the specific nutrient combination Fortasyn Connect. The effects of the medical food (Active) were compared with a control product (Control) that was isocaloric and similar in flavor and appearance to the active product but lacked the specific nutrient combination. Compared with the control product, the active product significantly improved memory performance in drug-naive patients with mild AD in both studies. Souvenir I study (A): percentage of patients showing decline, no change or improvement on the Wechsler Memory Scale-revised delayed verbal recall score after 12 weeks of supplementation with active or control product [172]. Souvenir II study (B): change from baseline in the Neuropsychological Test Battery memory composite score during 24 weeks of supplementation with active or control product, with a significant difference in trajectories over time between the groups $(p=0.023)$ [174]. Error bars represent standard errors. Figures are reprinted from Scheltens et al. [172] (A) and Scheltens et al. [174] (B), with permission from Elsevier and IOS Press, respectively.

lying synaptic function and neuronal communication. Quantitative EEG analyses and more advanced functional network analyses suggest that the intervention preserves functional brain connectivity [174] and the functional brain network organization (de Waal et al., submitted) in patients with mild $\mathrm{AD}$, counteracting the pattern usually seen in AD. These findings support the hypothesis that this medical food stimulates synapse formation and function in early AD.
The clinical studies to date provide evidence that Souvenaid is well tolerated and has a positive safety profile, including use in combination with current drug therapy for AD. In three large clinical trials, no differences were found in tolerance and safety measures between patients on the active product compared to patients on the control product [172-174]. This medical food has a beneficial effect on memory function in early $\mathrm{AD}$ and support the hypothesis that improving synaptic functioning in early $\mathrm{AD}$ may be related to improved memory performance. Since synaptic dysfunction already occurs in the early stages of $\mathrm{AD}$, targeting synaptic loss and membrane-related pathology with this intervention might be most efficacious when applied to earlier stages of AD, when damaging patho-physiological changes have not yet accumulated to an irreversible degree. Additional studies are ongoing to investigate the longer-term outcome of this intervention in early and prodromal AD to broaden the understanding of its clinical utility. These studies also include imaging and biomarker techniques in order to further investigate the mode of action of the specific nutrient combination Fortasyn Connect on synaptic dysfunction.

\section{ACKNOWLEDGMENTS}

Figures 1, 2, 4, and 5 were designed in collaboration with Medical Visuals, Maartje Kunen. All authors are employees of Nutricia Advanced Medical Nutrition, Nutricia Research, Utrecht, The Netherlands.

Authors' disclosures available online (http://www.jalz.com/disclosures/view.php?id=1881).

\section{REFERENCES}

[1] Caselli RJ, Beach TG, Yaari R, Reiman EM (2006) Alzheimer's disease a century later. J Clin Psychiatry 67, 1784-1800.

[2] Pereira C, Agostinho P, Moreira PI, Cardoso SM, Oliveira CR (2005) Alzheimer's disease-associated neurotoxic mechanisms and neuroprotective strategies. Curr Drug Targets CNS Neurol Disord 4, 383-403.

[3] Ballard C, Gauthier S, Corbett A, Brayne C, Aarsland D, Jones E (2011) Alzheimer's disease. Lancet 377, 1019-1031.

[4] Selkoe DJ (2002) Alzheimer's disease is a synaptic failure. Science 298, 789-791.

[5] Arendt T (2009) Synaptic degeneration in Alzheimer's disease. Acta Neuropathol 118, 167-179.

[6] Davies CA, Mann DM, Sumpter PQ, Yates PO (1987) A quantitative morphometric analysis of the neuronal and synaptic content of the frontal and temporal cortex in patients with Alzheimer's disease. J Neurol Sci 78, 151-164.

[7] Masliah E, Terry RD, Alford M, DeTeresa R, Hansen LA (1991) Cortical and subcortical patterns of synaptophysin- 
like immunoreactivity in Alzheimer's disease. Am J Pathol 138, 235-246.

[8] Koffie RM, Hyman BT, Spires-Jones TL (2011) Alzheimer's disease: Synapses gone cold. Mol Neurodegener 6, 63.

[9] Haass C, Selkoe DJ (2007) Soluble protein oligomers in neurodegeneration: Lessons from the Alzheimer's amyloid beta-peptide. Nat Rev Mol Cell Biol 8, 101-112.

[10] Sperling RA, Aisen PS, Beckett LA, Bennett DA, Craft S, Fagan AM, Iwatsubo T, Jack CR Jr, Kaye J, Montine TJ, Park DC, Reiman EM, Rowe CC, Siemers E, Stern Y, Yaffe K, Carrillo MC, Thies B, Morrison-Bogorad M, Wagster MV, Phelps CH (2011) Toward defining the preclinical stages of Alzheimer's disease: Recommendations from the National Institute on Aging-Alzheimer's Association workgroups on diagnostic guidelines for Alzheimer's disease. Alzheimers Dement 7, 280-292.

[11] Terry RD (2006) Alzheimer's disease and the aging brain. $J$ Geriatr Psychiatry Neurol 19, 125-128.

[12] Masliah E, Mallory M, Hansen L, DeTeresa R, Terry RD (1993) Quantitative synaptic alterations in the human neocortex during normal aging. Neurology 43, 192-197.

[13] Liu X, Erikson C, Brun A (1996) Cortical synaptic changes and gliosis in normal aging, Alzheimer's disease and frontal lobe degeneration. Dementia 7, 128-134.

[14] Terry RD, Masliah E, Salmon DP, Butters N, DeTeresa R, Hill R, Hansen LA, Katzman R (1991) Physical basis of cognitive alterations in Alzheimer's disease: Synapse loss is the major correlate of cognitive impairment. Ann Neurol 30, 572-580.

[15] DeKosky ST, Scheff SW (1990) Synapse loss in frontal cortex biopsies in Alzheimer's disease: Correlation with cognitive severity. Ann Neurol 27, 457-464.

[16] Scheff SW, Price DA, Schmitt FA, Mufson EJ (2006) Hippocampal synaptic loss in early Alzheimer's disease and mild cognitive impairment. Neurobiol Aging 27, 1372-1384.

[17] Scheff SW, Price DA, Schmitt FA, Scheff MA, Mufson EJ (2011) Synaptic loss in the inferior temporal gyrus in mild cognitive impairment and Alzheimer's disease. JAlzheimers Dis 24, 547-557.

[18] Scheff SW, Price DA, Schmitt FA, DeKosky ST, Mufson EJ (2007) Synaptic alterations in CA1 in mild Alzheimer disease and mild cognitive impairment. Neurology 68, 15011508.

[19] Mosconi L, Pupi A, De Leon MJ (2008) Brain glucose hypometabolism and oxidative stress in preclinical Alzheimer's disease. Ann N Y Acad Sci 1147, 180-195.

[20] Herholz K (2012) Use of FDG PET as an imaging biomarker in clinical trials of Alzheimer's disease. Biomark Med 6, 431-439.

[21] Brickman AM, Small SA, Fleisher A (2009) Pinpointing synaptic loss caused by Alzheimer's disease with fMRI. Behav Neurol 21, 93-100.

[22] Siegel M, Donner TH, Engel AK (2012) Spectral fingerprints of large-scale neuronal interactions. Nat Rev Neurosci 13, 121-134.

[23] Stam CJ (2011) Dementia and EEG. In Niedermeyer's Electroencephalography: Basic Principles, Clinical Applications and Related Fields, Schomer DL, Lopes da Silva FH, eds. Lippincott Williams \& Wilkins/Wolters Kluwer, Philadelphia, PA, pp. 375-394.

[24] Cook IA, Leuchter AF (1996) Synaptic dysfunction in Alzheimer's disease: Clinical assessment using quantitative EEG. Behav Brain Res 78, 15-23.
[25] de Wilde MC, Kamphuis PJ, Sijben JW, Scheltens P (2011) Utility of imaging for nutritional intervention studies in Alzheimer's disease. Eur J Pharmacol 668(Suppl 1), S59S69.

[26] Sperling RA, Karlawish J, Johnson KA (2013) Preclinical Alzheimer disease-the challenges ahead. Nat Rev Neurol 9 , 54-58.

[27] van Meer G, Voelker DR, Feigenson GW (2008) Membrane lipids: Where they are and how they behave. Nat Rev Mol Cell Biol 9, 112-124.

[28] Mielke MM, Lyketsos CG (2006) Lipids and the pathogenesis of Alzheimer's disease: Is there a link? Int Rev Psychiatry 18, 173-186.

[29] Nitsch RM, Blusztajn JK, Pittas AG, Slack BE, Growdon JH, Wurtman RJ (1992) Evidence for a membrane defect in Alzheimer disease brain. Proc Natl Acad Sci U S A 89, 1671-1675.

[30] Gottfries CG, Karlsson I, Svennerholm L (1996) Membrane components separate early-onset Alzheimer's disease from senile dementia of the Alzheimer type. Int Psychogeriatr $\mathbf{8}$, 365-372.

[31] Prasad MR, Lovell MA, Yatin M, Dhillon H, Markesbery WR (1998) Regional membrane phospholipid alterations in Alzheimer's disease. Neurochem Res 23, 81-88.

[32] Pettegrew JW, Panchalingam K, Hamilton RL, McClure RJ (2001) Brain membrane phospholipid alterations in Alzheimer's disease. Neurochem Res 26, 771-782.

[33] Grimm MO, Grosgen S, Riemenschneider M, Tanila H, Grimm HS, Hartmann T (2011) From brain to food: Analysis of phosphatidylcholins, lyso-phosphatidylcholins and phosphatidylcholin-plasmalogens derivates in Alzheimer's disease human post mortem brains and mice model via mass spectrometry. J Chromatogr A 1218, 7713-7722.

[34] Igarashi M, Ma K, Gao F, Kim HW, Rapoport SI, Rao JS (2011) Disturbed choline plasmalogen and phospholipid fatty acid concentrations in Alzheimer's disease prefrontal cortex. J Alzheimers Dis 24, 507-517.

[35] Grimm MO, Kuchenbecker J, Rothhaar TL, Grosgen S, Hundsdorfer B, Burg VK, Friess P, Muller U, Grimm HS, Riemenschneider M, Hartmann T (2011) Plasmalogen synthesis is regulated via alkyl-dihydroxyacetonephosphatesynthase by amyloid precursor protein processing and is affected in Alzheimer's disease. J Neurochem 116, 916925.

[36] Soderberg M, Edlund C, Kristensson K, Dallner G (1991) Fatty acid composition of brain phospholipids in aging and in Alzheimer's disease. Lipids 26, 421-425.

[37] Astarita G, Jung KM, Berchtold NC, Nguyen VQ, Gillen DL, Head E, Cotman CW, Piomelli D (2010) Deficient liver biosynthesis of docosahexaenoic acid correlates with cognitive impairment in Alzheimer's disease. PLoS One 5, e12538.

[38] Nakada T, Kwee IL, Ellis WG (1990) Membrane fatty acid composition shows delta-6-desaturase abnormalities in Alzheimer's disease. Neuroreport 1, 153-155.

[39] Cunnane SC, Schneider JA, Tangney C, Tremblay-Mercier J, Fortier M, Bennett DA, Morris MC (2012) Plasma and brain fatty acid profiles in mild cognitive impairment and Alzheimer's disease. J Alzheimers Dis 29, 691-697.

[40] Martin V, Fabelo N, Santpere G, Puig B, Marin R, Ferrer I, Diaz M (2010) Lipid alterations in lipid rafts from Alzheimer's disease human brain cortex. J Alzheimers Dis 19, 489-502.

[41] Han X (2010) Multi-dimensional mass spectrometry-based shotgun lipidomics and the altered lipids at the mild cog- 
nitive impairment stage of Alzheimer's disease. Biochim Biophys Acta 1801, 774-783.

[42] Yehuda S, Rabinovitz S, Carasso RL, Mostofsky DI (2002) The role of polyunsaturated fatty acids in restoring the aging neuronal membrane. Neurobiol Aging 23, 843-853.

[43] Haag M (2003) Essential fatty acids and the brain. Can J Psychiatry 48, 195-203.

[44] Vigh L, Escriba PV, Sonnleitner A, Sonnleitner M, Piotto S, Maresca B, Horvath I, Harwood JL (2005) The significance of lipid composition for membrane activity: New concepts and ways of assessing function. Prog Lipid Res 44, 303344.

[45] Bourre JM (2006) Effects of nutrients (in food) on the structure and function of the nervous system: Update on dietary requirements for brain. Part 2: Macronutrients. JNutr Health Aging 10, 386-399.

[46] Bourre JM (2006) Effects of nutrients (in food) on the structure and function of the nervous system: Update on dietary requirements for brain. Part 1: Micronutrients. J Nutr Health Aging 10, 377-385.

[47] Sastry PS (1985) Lipids of nervous tissue: Composition and metabolism. Prog Lipid Res 24, 69-176.

[48] Kennedy EP, Weiss SB (1956) The function of cytidine coenzymes in the biosynthesis of phospholipides. J Biol Chem 222, 193-214.

[49] Vance JE, Vance DE (2004) Phospholipid biosynthesis in mammalian cells. Biochem Cell Biol 82, 113-128.

[50] Wurtman RJ, Cansev M, Sakamoto T, Ulus IH (2009) Use of phosphatide precursors to promote synaptogenesis. Annu Rev Nutr 29, 59-87.

[51] Liu SY, Tardi PG, Choy PC, Man RY (1993) Effects of selenium supplement on the de novo biosynthesis of glycerolipids in the isolated rat heart. Biochim Biophys Acta 1170, 307-313.

[52] Richardson UI, Watkins CJ, Pierre C, Ulus IH, Wurtman RJ (2003) Stimulation of CDP-choline synthesis by uridine or cytidine in PC12 rat pheochromocytoma cells. Brain Res 971, 161-167.

[53] Pooler AM, Guez DH, Benedictus R, Wurtman RJ (2005) Uridine enhances neurite outgrowth in nerve growth factordifferentiated PC12. Neuroscience 134, 207-214.

[54] Wurtman RJ, Regan M, Ulus I, Yu L (2000) Effect of oral CDP-choline on plasma choline and uridine levels in humans. Biochem Pharmacol 60, 989-992.

[55] Ulus IH, Watkins CJ, Cansev M, Wurtman RJ (2006) Cytidine and uridine increase striatal CDP-choline levels without decreasing acetylcholine synthesis or release. $\mathrm{Cell} \mathrm{Mol} \mathrm{Neu-}$ robiol 26, 563-577.

[56] Millington WR, Wurtman RJ (1982) Choline administration elevates brain phosphorylcholine concentrations. $\mathrm{J} \mathrm{Neu}$ rochem 38, 1748-1752.

[57] Cansev M, Watkins CJ, van der Beek EM, Wurtman RJ (2005) Oral uridine-5'-monophosphate (UMP) increases brain CDP-choline levels in gerbils. Brain Res 1058, 101108.

[58] Agarwal N, Sung YH, Jensen JE, daCunha G, Harper D, Olson D, Renshaw PF (2010) Short-term administration of uridine increases brain membrane phospholipid precursors in healthy adults: A 31-phosphorus magnetic resonance spectroscopy study at 4T. Bipolar Disord 12, 825-833.

[59] Richardson UI, Wurtman RJ (2007) Polyunsaturated fatty acids stimulate phosphatidylcholine synthesis in PC12 cells. Biochim Biophys Acta 1771, 558-563.

[60] Cansev M, Wurtman RJ (2007) Chronic administration of docosahexaenoic acid or eicosapentaenoic acid, but not arachidonic acid, alone or in combination with uridine, increases brain phosphatide and synaptic protein levels in gerbils. Neuroscience 148, 421-431.

[61] Cansev M, Marzloff G, Sakamoto T, Ulus IH, Wurtman RJ (2009) Giving uridine and/or docosahexaenoic acid orally to rat dams during gestation and nursing increases synaptic elements in brains of weanling pups. Dev Neurosci 31, 181192.

[62] Cansev M, Ulus IH, Wang L, Maher TJ, Wurtman RJ (2008) Restorative effects of uridine plus docosahexaenoic acid in a rat model of Parkinson's disease. Neurosci Res 62, 206-209.

[63] Holguin S, Huang Y, Liu J, Wurtman R (2008) Chronic administration of DHA and UMP improves the impaired memory of environmentally impoverished rats. Behav Brain Res 191, 11-16.

[64] Holguin S, Martinez J, Chow C, Wurtman R (2008) Dietary uridine enhances the improvement in learning and memory produced by administering DHA to gerbils. FASEB $J \mathbf{2 2}$, 3938-3946.

[65] Sakamoto T, Cansev M, Wurtman RJ (2007) Oral supplementation with docosahexaenoic acid and uridine-5'monophosphate increases dendritic spine density in adult gerbil hippocampus. Brain Res 1182, 50-59.

[66] Wurtman RJ, Ulus IH, Cansev M, Watkins CJ, Wang L, Marzloff G (2006) Synaptic proteins and phospholipids are increased in gerbil brain by administering uridine plus docosahexaenoic acid orally. Brain Res 1088, 83-92.

[67] Moore SA, Yoder E, Murphy S, Dutton GR, Spector AA (1991) Astrocytes, not neurons, produce docosahexaenoic acid (22:6 omega-3) and arachidonic acid (20:4 omega-6). J Neurochem 56, 518-524.

[68] Hashimoto M, Hossain S, Tanabe Y, Kawashima A, Harada T, Yano T, Mizuguchi K, Shido O (2009) The protective effect of dietary eicosapentaenoic acid against impairment of spatial cognition learning ability in rats infused with amyloid beta(1-40). J Nutr Biochem 20, 965-973.

[69] Wang CS, Lee RK (2000) Choline plus cytidine stimulate phospholipid production, and the expression and secretion of amyloid precursor protein in rat PC12 cells. Neurosci Lett 283, 25-28.

[70] Akbar M, Calderon F, Wen Z, Kim HY (2005) Docosahexaenoic acid: A positive modulator of Akt signaling in neuronal survival. Proc Natl Acad Sci U S A 102, 1085810863.

[71] Shahdat H, Hashimoto M, Shimada T, Shido O (2004) Synaptic plasma membrane-bound acetylcholinesterase activity is not affected by docosahexaenoic acid-induced decrease in membrane order. Life Sci 74, 3009-3024.

[72] de Wilde MC, Penke B, van der Beek EM, Kuipers AA, Kamphuis PJ, Broersen LM (2011) Neuroprotective effects of a specific multi-nutrient intervention against Abeta42induced toxicity in rats. J Alzheimers Dis 27, 327-339.

[73] Arterburn LM, Hall EB, Oken H (2006) Distribution, interconversion, and dose response of n-3 fatty acids in humans. Am J Clin Nutr 83, 1467S-1476S.

[74] Wurtman RJ, Hirsch MJ, Growdon JH (1977) Lecithin consumption raises serum-free-choline levels. Lancet $\mathbf{2}$, 68-69.

[75] Smith AD, Smith SM, de Jager CA, Whitbread P, Johnston C, Agacinski G, Oulhaj A, Bradley KM, Jacoby R, Refsum H (2010) Homocysteine-lowering by B vitamins slows the rate of accelerated brain atrophy in mild cognitive impairment: A randomized controlled trial. PLoS One 5, e12244.

[76] Cansev M (2006) Uridine and cytidine in the brain: Their transport and utilization. Brain Res Rev 52, 389-397. 
[77] Rapoport SI, Chang MC, Spector AA (2001) Delivery and turnover of plasma-derived essential PUFAs in mammalian brain. J Lipid Res 42, 678-685.

[78] Connor WE, Neuringer M, Lin DS (1990) Dietary effects on brain fatty acid composition: The reversibility of $n-3$ fatty acid deficiency and turnover of docosahexaenoic acid in the brain, erythrocytes, and plasma of rhesus monkeys. J Lipid Res 31, 237-247.

[79] Brossard N, Croset M, Lecerf J, Pachiaudi C, Normand S, Chirouze V, Macovschi O, Riou JP, Tayot JL, Lagarde M (1996) Metabolic fate of an oral tracer dose of [13C]docosahexaenoic acid triglycerides in the rat. Am J Physiol 270, R846-R854.

[80] Cohen EL, Wurtman RJ (1976) Brain acetylcholine: Control by dietary choline. Science 191, 561-562.

[81] Klein J, Koppen A, Loffelholz K (1990) Small rises in plasma choline reverse the negative arteriovenous difference of brain choline. J Neurochem 55, 1231-1236.

[82] Yan J, Wang W, Gregory JF 3rd, Malysheva O, Brenna JT, Stabler SP, Allen RH, Caudill MA (2011) MTHFR C677T genotype influences the isotopic enrichment of onecarbon metabolites in folate-compromised men consuming d9-choline. Am J Clin Nutr 93, 348-355.

[83] Park EI, Garrow TA (1999) Interaction between dietary methionine and methyl donor intake on rat liver betainehomocysteine methyltransferase gene expression and organization of the human gene. J Biol Chem 274, 78167824.

[84] Jacob RA, Jenden DJ, Allman-Farinelli MA, Swendseid ME (1999) Folate nutriture alters choline status of women and men fed low choline diets. J Nutr 129, 712-717.

[85] Holm PI, Bleie O, Ueland PM, Lien EA, Refsum H, Nordrehaug JE, Nygard O (2004) Betaine as a determinant of postmethionine load total plasma homocysteine before and after B-vitamin supplementation. Arterioscler Thromb Vasc Biol 24, 301-307.

[86] Watkins SM, Zhu X, Zeisel SH (2003) Phosphatidylethanolamine-N-methyltransferase activity and dietary choline regulate liver-plasma lipid flux and essential fatty acid metabolism in mice. $J$ Nutr $\mathbf{1 3 3}$, 3386-3391.

[87] Selley ML (2007) A metabolic link between Sadenosylhomocysteine and polyunsaturated fatty acid metabolism in Alzheimer's disease. Neurobiol Aging 28, 1834-1839.

[88] Pynn CJ, Henderson NG, Clark H, Koster G, Bernhard W, Postle AD (2011) Specificity and rate of human and mouse liver and plasma phosphatidylcholine synthesis analyzed in vivo. J Lipid Res 52, 399-407.

[89] van Wijk N, Watkins CJ, Bohlke M, Maher TJ, Hageman RJ, Kamphuis PJ, Broersen LM, Wurtman RJ (2012) Plasma choline concentration varies with different dietary levels of vitamins B6, B12 and folic acid in rats maintained on choline-adequate diets. Br J Nutr 107, 1408-1412.

[90] van Wijk N, Watkins CJ, Hageman RJ, Sijben JW, Kamphuis PJ, Wurtman RJ, Broersen LM (2012) Combined dietary folate, vitamin B-12, and vitamin B-6 intake influences plasma docosahexaenoic acid concentration in rats. Nutr Metab 9, 49.

[91] Van Dam F, Van Gool WA (2009) Hyperhomocysteinemia and Alzheimer's disease: A systematic review. Arch Gerontol Geriatr 48, 425-430.

[92] Magil SG, Zeisel SH, Wurtman RJ (1981) Effects of ingesting soy or egg lecithins on serum choline, brain choline and brain acetylcholine. J Nutr 111, 166-170.
[93] van Wijk N, Hageman RJ, Kamphuis PJ, Broersen LM, Sijben JW (2011) Specific nutrients to increase availability of components involved in neuronal membrane synthesis. Alzheimers Dement 7, S665-S666.

[94] Jones DB, Hancock JD, Harmon DL, Walker CE (1992) Effects of exogenous emulsifiers and fat sources on nutrient digestibility, serum lipids, and growth performance in weanling pigs. J Anim Sci 70, 3473-3482.

[95] O'Doherty PJ, Kakis G, Kuksis A (1973) Role of luminal lecithin in intestinal fat absorption. Lipids 8, 249-255.

[96] Nishimukai M, Hara H (2007) Soybean phosphatidylcholine-induced enhancement of lymphatic absorption of triglyceride depends on chylomicron formation in rats. Biosci Biotechnol Biochem 71, 1192-1197.

[97] Cybulski LE, de Mendoza D (2011) Bilayer hydrophobic thickness and integral membrane protein function. Curr Protein Pept Sci 12, 760-766.

[98] Andersen OS, Koeppe RE 2nd (2007) Bilayer thickness and membrane protein function: An energetic perspective. Annu Rev Biophys Biomol Struct 36, 107-130.

[99] Eyster KM (2007) The membrane and lipids as integral participants in signal transduction: Lipid signal transduction for the non-lipid biochemist. Adv Physiol Educ 31, 5-16.

[100] Farooqui AA (2012) Lipid mediators and their metabolism in the nucleous: Implications for Alzheimer's disease. J Alzheimers Dis 30(Suppl 2), S163-S178.

[101] de Wilde MC, van der Beek EM, Kiliaan AJ, Leenders I, Kuipers AA, Kamphuis PJ, Broersen LM (2010) Docosahexaenoic acid reduces amyloid-beta secretion in human AbetaPP-transfected CHO-cells by mechanisms other than inflammation related to PGE. J Alzheimers Dis 21, 12711281.

[102] Hashimoto M, Hossain S, Shimada T, Shido O (2006) Docosahexaenoic acid-induced protective effect against impaired learning in amyloid beta-infused rats is associated with increased synaptosomal membrane fluidity. Clin Exp Pharmacol Physiol 33, 934-939.

[103] Favreliere S, Perault MC, Huguet F, De Javel D, Bertrand N, Piriou A, Durand G (2003) DHA-enriched phospholipid diets modulate age-related alterations in rat hippocampus. Neurobiol Aging 24, 233-243.

[104] de Wilde MC, Hogyes E, Kiliaan AJ, Farkas T, Luiten PG, Farkas E (2003) Dietary fatty acids alter blood pressure, behavior and brain membrane composition of hypertensive rats. Brain Res 988, 9-19.

[105] Broersen LM, Kuipers AA, Balvers M, van Wijk N, Savelkoul PJ, de Wilde MC, van der Beek EM, Sijben JW, Hageman RJ, Kamphuis PJ, Kiliaan AJ (2013) A specific multinutrient diet reduces Alzheimer-like pathology in young adult AbetaPPswe/PS1dE9 mice. J Alzheimers Dis 33, 177190.

[106] Axelsen PH, Komatsu H, Murray IV (2011) Oxidative stress and cell membranes in the pathogenesis of Alzheimer's disease. Physiology 26, 54-69.

[107] Gutteridge JM (1995) Lipid peroxidation and antioxidants as biomarkers of tissue damage. Clin Chem 41, 1819-1828.

[108] Switzer BR, Summer GK (1972) Collagen synthesis in human skin fibroblasts: Effects of ascorbate, -ketoglutarate and ferrous ion on proline hydroxylation. J Nutr 102, 721728.

[109] Fox MA, Sanes JR, Borza DB, Eswarakumar VP, Fassler R, Hudson BG, John SW, Ninomiya Y, Pedchenko V, Pfaff SL, Rheault MN, Sado Y, Segal Y, Werle MJ, Umemori H 
(2007) Distinct target-derived signals organize formation, maturation, and maintenance of motor nerve terminals. Cell 129, 179-193.

[110] Peters MM, Hill KE, Burk RF, Weeber EJ (2006) Altered hippocampus synaptic function in selenoprotein $\mathrm{P}$ deficient mice. Mol Neurodegener 1, 12.

[111] Lucy JA (1972) Functional and structural aspects of biological membranes: A suggested structural role for vitamin $\mathrm{E}$ in the control of membrane permeability and stability. Ann N Y Acad Sci 203, 4-11.

[112] Quinn PJ (2004) Is the distribution of alpha-tocopherol in membranes consistent with its putative functions? Biochemistry 69, 58-66.

[113] Monroe EB, Jurchen JC, Lee J, Rubakhin SS, Sweedler JV (2005) Vitamin E imaging and localization in the neuronal membrane. J Am Chem Soc 127, 12152-12153.

[114] Trachtenberg JT, Chen BE, Knott GW, Feng G, Sanes JR, Welker E, Svoboda K (2002) Long-term in vivo imaging of experience-dependent synaptic plasticity in adult cortex. Nature 420, 788-794.

[115] Lardi-Studler B, Fritschy JM (2007) Matching of pre- and postsynaptic specializations during synaptogenesis. Neuroscientist 13, 115-126.

[116] Wurtman RJ, Cansev M, Sakamoto T, Ulus I (2010) Nutritional modifiers of aging brain function: Use of uridine and other phosphatide precursors to increase formation of brain synapses. Nutr Rev 68(Suppl 2), S88-101.

[117] Cansev M, Wurtman RJ, Sakamoto T, Ulus IH (2008) Oral administration of circulating precursors for membrane phosphatides can promote the synthesis of new brain synapses. Alzheimers Dement 4, S153-S168.

[118] Calderon F, Kim HY (2004) Docosahexaenoic acid promotes neurite growth in hippocampal neurons. J Neurochem 90, 979-988.

[119] Cao D, Kevala K, Kim J, Moon HS, Jun SB, Lovinger D, Kim HY (2009) Docosahexaenoic acid promotes hippocampal neuronal development and synaptic function. J Neurochem 111, 510-521

[120] He C, Qu X, Cui L, Wang J, Kang JX (2009) Improved spatial learning performance of fat- 1 mice is associated with enhanced neurogenesis and neuritogenesis by docosahexaenoic acid. Proc Natl Acad Sci U S A 106, 11370-11375.

[121] Shrivastava R, Vincent B, Gobron S, Cucuat N, John GW (2005) Evidence for growth-promoting effects of omega n-3 fatty acids alone and in combination with a specific vitamin and mineral complex in rat neuroblastoma cells. Nutr Neurosci 8, 317-321.

[122] Fujii A, Matsumoto H, Yamamoto H (1996) Effect of vitamin B complex on neurotransmission and neurite outgrowth. Gen Pharmacol 27, 995-1000.

[123] Wang L, Pooler AM, Albrecht MA, Wurtman RJ (2005) Dietary uridine- $5^{\prime}$-monophosphate supplementation increases potassium-evoked dopamine release and promotes neurite outgrowth in aged rats. J Mol Neurosci 27, 137-145.

[124] Calon F, Lim GP, Yang F, Morihara T, Teter B, Ubeda O, Rostaing P, Triller A, Salem N Jr, Ashe KH, Frautschy SA, Cole GM (2004) Docosahexaenoic acid protects from dendritic pathology in an Alzheimer's disease mouse model. Neuron 43, 633-645.

[125] Toni N, Teng EM, Bushong EA, Aimone JB, Zhao C, Consiglio A, van Praag H, Martone ME, Ellisman MH, Gage FH (2007) Synapse formation on neurons born in the adult hippocampus. Nat Neurosci 10, 727-734.

[126] Knott GW, Holtmaat A, Wilbrecht L, Welker E, Svoboda K (2006) Spine growth precedes synapse formation in the adult neocortex in vivo. Nat Neurosci 9, 11171124.

[127] Aid S, Vancassel S, Linard A, Lavialle M, Guesnet P (2005) Dietary docosahexaenoic acid [22:6(n-3)] as a phospholipid or a triglyceride enhances the potassium chloride-evoked release of acetylcholine in rat hippocampus. J Nutr 135, 1008-1013.

[128] Aid S, Vancassel S, Poumes-Ballihaut C, Chalon S, Guesnet P, Lavialle M (2003) Effect of a diet-induced n-3 PUFA depletion on cholinergic parameters in the rat hippocampus. $J$ Lipid Res 44, 1545-1551.

[129] Wang L, Albrecht MA, Wurtman RJ (2007) Dietary supplementation with uridine-5'-monophosphate (UMP), a membrane phosphatide precursor, increases acetylcholine level and release in striatum of aged rat. Brain Res $\mathbf{1 1 3 3}$, 42-48.

[130] Ulus IH, Wurtman RJ, Mauron C, Blusztajn JK (1989) Choline increases acetylcholine release and protects against the stimulation-induced decrease in phosphatide levels within membranes of rat corpus striatum. Brain Res 484, 217-227.

[131] Beninger RJ, Tighe SA, Jhamandas K (1984) Effects of chronic manipulations of dietary choline on locomotor activity, discrimination learning and cortical acetylcholine release in aging adult Fisher 344 rats. Neurobiol Aging 5, 29-34.

[132] Savelkoul PJ, Janickova H, Kuipers AA, Hageman RJ, Kamphuis PJ, Dolezal V, Broersen LM (2012) A specific multi-nutrient formulation enhances M1 muscarinic acetylcholine receptor responses in vitro. J Neurochem $\mathbf{1 2 0}$, 631-640.

[133] Kihara T, Shimohama S (2004) Alzheimer's disease and acetylcholine receptors. Acta Neurobiol Exp 64, 99-105.

[134] Calon F, Lim GP, Morihara T, Yang F, Ubeda O, Salem N Jr, Frautschy SA, Cole GM (2005) Dietary n-3 polyunsaturated fatty acid depletion activates caspases and decreases NMDA receptors in the brain of a transgenic mouse model of Alzheimer's disease. Eur J Neurosci 22, 617-626.

[135] Farkas E, de Wilde MC, Kiliaan AJ, Meijer J, Keijser JN, Luiten PG (2002) Dietary long chain PUFAs differentially affect hippocampal muscarinic 1 and serotonergic 1 A receptors in experimental cerebral hypoperfusion. Brain Res $\mathbf{9 5 4}$, 32.

[136] Shankar GM, Bloodgood BL, Townsend M, Walsh DM, Selkoe DJ, Sabatini BL (2007) Natural oligomers of the Alzheimer amyloid-beta protein induce reversible synapse loss by modulating an NMDA-type glutamate receptordependent signaling pathway. J Neurosci 27, 2866-2875.

[137] Shankar GM, Li S, Mehta TH, Garcia-Munoz A, Shepardson NE, Smith I, Brett FM, Farrell MA, Rowan MJ, Lemere CA, Regan CM, Walsh DM, Sabatini BL, Selkoe DJ (2008) Amyloid-beta protein dimers isolated directly from Alzheimer's brains impair synaptic plasticity and memory. Nat Med 14, 837-842.

[138] Bittner T, Burgold S, Dorostkar MM, Fuhrmann M, Wegenast-Braun BM, Schmidt B, Kretzschmar H, Herms J (2012) Amyloid plaque formation precedes dendritic spine loss. Acta Neuropathol 124, 797-807.

[139] Williamson R, Sutherland C (2011) Neuronal membranes are key to the pathogenesis of Alzheimer's disease: The role of both raft and non-raft membrane domains. Curr Alzheimer Res 8, 213-221.

[140] Eckert GP, Wood WG, Muller WE (2010) Lipid membranes and beta-amyloid: A harmful connection. Curr Protein Pept Sci 11, 319-325. 
[141] Florent-Bechard S, Desbene C, Garcia P, Allouche A, Youssef I, Escanye MC, Koziel V, Hanse M, MalaplateArmand C, Stenger C, Kriem B, Yen-Potin FT, Olivier JL, Pillot T, Oster T (2009) The essential role of lipids in Alzheimer's disease. Biochimie 91, 804-809.

[142] Hartmann T, Kuchenbecker J, Grimm MO (2007) Alzheimer's disease: The lipid connection. J Neurochem 103(Suppl 1), 159-170.

[143] Grimm MO, Kuchenbecker J, Grosgen S, Burg VK, Hundsdorfer B, Rothhaar TL, Friess P, de Wilde MC, Broersen LM, Penke B, Peter M, Vigh L, Grimm HS, Hartmann T (2011) Docosahexaenoic acid reduces amyloid beta production via multiple pleiotropic mechanisms. J Biol Chem 286, 14028-14039.

[144] Wolozin B (2001) A fluid connection: Cholesterol and Abeta. Proc Natl Acad Sci U S A 98, 5371-5373.

[145] Winkler E, Kamp F, Scheuring J, Ebke A, Fukumori A, Steiner H (2012) Generation of Alzheimer diseaseassociated amyloid beta42/43 peptide by gamma-secretase can be inhibited directly by modulation of membrane thickness. J Biol Chem 287, 21326-21334.

[146] Sahlin C, Pettersson FE, Nilsson LN, Lannfelt L, Johansson AS (2007) Docosahexaenoic acid stimulates nonamyloidogenic APP processing resulting in reduced Abeta levels in cellular models of Alzheimer's disease. Eur J Neurosci 26, 882-889.

[147] Oksman M, Iivonen H, Hogyes E, Amtul Z, Penke B, Leenders I, Broersen L, Lutjohann D, Hartmann T, Tanila H (2006) Impact of different saturated fatty acid, polyunsaturated fatty acid and cholesterol containing diets on beta-amyloid accumulation in APP/PS1 transgenic mice. Neurobiol Dis 23, 563-572.

[148] Florent S, Malaplate-Armand C, Youssef I, Kriem B, Koziel V, Escanye MC, Fifre A, Sponne I, Leininger-Muller B, Olivier JL, Pillot T, Oster T (2006) Docosahexaenoic acid prevents neuronal apoptosis induced by soluble amyloidbeta oligomers. J Neurochem 96, 385-395.

[149] Amtul Z, Uhrig M, Supino R, Beyreuther K (2010) Phospholipids and a phospholipid-rich diet alter the in vitro amyloid-beta peptide levels and amyloid-beta 42/40 ratios. Neurosci Lett 481, 73-77.

[150] Fuso A, Nicolia V, Cavallaro RA, Ricceri L, D’Anselmi F, Coluccia P, Calamandrei G, Scarpa S (2008) B-vitamin deprivation induces hyperhomocysteinemia and brain S-adenosylhomocysteine, depletes brain Sadenosylmethionine, and enhances PS1 and BACE expression and amyloid-beta deposition in mice. Mol Cell Neurosci 37, 731-746.

[151] Zhuo JM, Pratico D (2010) Acceleration of brain amyloidosis in an Alzheimer's disease mouse model by a folate, vitamin B6 and B12-deficient diet. Exp Gerontol 45, 195201.

[152] Conte V, Uryu K, Fujimoto S, Yao Y, Rokach J, Longhi L, Trojanowski JQ, Lee VM, McIntosh TK, Pratico D (2004) Vitamin E reduces amyloidosis and improves cognitive function in $\mathrm{Tg} 2576$ mice following repetitive concussive brain injury. J Neurochem 90, 758-764.

[153] Sung S, Yao Y, Uryu K, Yang H, Lee VM, Trojanowski JQ, Pratico D (2004) Early vitamin E supplementation in young but not aged mice reduces Abeta levels and amyloid deposition in a transgenic model of Alzheimer's disease. FASEB J 18, 323-325.

[154] Lim GP, Calon F, Morihara T, Yang F, Teter B, Ubeda O, Salem N Jr, Frautschy SA, Cole GM (2005) A diet enriched with the omega-3 fatty acid docosahexaenoic acid reduces amyloid burden in an aged Alzheimer mouse model. $J \mathrm{Neu}$ rosci 25, 3032-3040.

[155] Green KN, Martinez-Coria H, Khashwji H, Hall EB, Yurko-Mauro KA, Ellis L, LaFerla FM (2007) Dietary docosahexaenoic acid and docosapentaenoic acid ameliorate amyloid-beta and tau pathology via a mechanism involving presenilin 1 levels. J Neurosci 27, 4385-4395.

[156] Hooijmans CR, Van der Zee CE, Dederen PJ, Brouwer KM, Reijmer YD, van Groen T, Broersen LM, Lutjohann D, Heerschap A, Kiliaan AJ (2009) DHA and cholesterol containing diets influence Alzheimer-like pathology, cognition and cerebral vasculature in APPswe/PS1dE9 mice. Neurobiol Dis 33, 482-498.

[157] Hooijmans CR, Rutters F, Dederen PJ, Gambarota G, Veltien A, van Groen T, Broersen LM, Lutjohann D, Heerschap A, Tanila H, Kiliaan AJ (2007) Changes in cerebral blood volume and amyloid pathology in aged Alzheimer APP/PS1 mice on a docosahexaenoic acid (DHA) diet or cholesterol enriched Typical Western Diet (TWD). Neurobiol Dis 28, 16-29.

[158] Arendash GW, Jensen MT, Salem N Jr, Hussein N, Cracchiolo J, Dickson A, Leighty R, Potter H (2007) A diet high in omega-3 fatty acids does not improve or protect cognitive performance in Alzheimer's transgenic mice. Neuroscience 149, 286-302.

[159] Arsenault D, Julien C, Tremblay C, Calon F (2011) DHA improves cognition and prevents dysfunction of entorhinal cortex neurons in 3xTg-AD mice. PLoS One 6, e17397.

[160] Gamoh S, Hashimoto M, Sugioka K, Shahdat HM, Hata N, Misawa Y, Masumura S (1999) Chronic administration of docosahexaenoic acid improves reference memory-related learning ability in young rats. Neuroscience 93, 237-241.

[161] Hashimoto M, Hossain S, Shimada T, Sugioka K, Yamasaki H, Fujii Y, Ishibashi Y, Oka J, Shido O (2002) Docosahexaenoic acid provides protection from impairment of learning ability in Alzheimer's disease model rats. J Neurochem $\mathbf{8 1}$, 1084-1091.

[162] Hashimoto M, Tanabe Y, Fujii Y, Kikuta T, Shibata H, Shido O (2005) Chronic administration of docosahexaenoic acid ameliorates the impairment of spatial cognition learning ability in amyloid beta-infused rats. J Nutr 135, 549555.

[163] Petursdottir AL, Farr SA, Morley JE, Banks WA, Skuladottir GV (2008) Effect of dietary n-3 polyunsaturated fatty acids on brain lipid fatty acid composition, learning ability, and memory of senescence-accelerated mouse. J Gerontol A Biol Sci Med Sci 63, 1153-1160.

[164] Teather LA, Wurtman RJ (2006) Chronic administration of UMP ameliorates the impairment of hippocampaldependent memory in impoverished rats. J Nutr 136, 2834-2837.

[165] Lim SY, Suzuki H (2000) Intakes of dietary docosahexaenoic acid ethyl ester and egg phosphatidylcholine improve maze-learning ability in young and old mice. J Nutr 130, 1629-1632.

[166] De Bruin NM, Kiliaan AJ, De Wilde MC, Broersen LM (2003) Combined uridine and choline administration improves cognitive deficits in spontaneously hypertensive rats. Neurobiol Learn Mem 80, 63-79.

[167] de Wilde M, Farkas E, Gerrits M, Kiliaan A, Luiten P (2002) The effect of $n-3$ polyunsaturated fatty acid-rich diets on cognitive and cerebrovascular parameters in chronic cerebral hypoperfusion. Brain Res 947, 166.

[168] Wiesmann M, Jansen D, Zerbi V, Broersen LM, Garthe A, Kiliaan AJ (2013) Improved spatial learning strategy and 
memory in aged Alzheimer AbetaPPswe/PS1dE9 mice on a multi-nutrient diet. J Alzheimers Dis 37, 233-245.

[169] Broersen LM, Koivisto H, Takalo M, Miettinen P, Tanila $\mathrm{H}$ (2011) Special lipid-based diets alleviate cognitive deficits in the APPswe/PS1dE9 transgenic mouse model of Alzheimer's disease independent of brain amyloid deposition. Alzheimers Dement 7, S650.

[170] Mi W, van Wijk N, Cansev M, Sijben JW, Kamphuis PJ (2013) Nutritional approaches in the risk reduction and management of Alzheimer's disease. Nutrition 29, 1080-1989.

[171] Lopes da Silva S, Vellas B, Elemans S, Luchsinger J, Kamphuis P, Yaffe K, Sijben J, Groenendijk M, Stijnen T (2013) Plasma nutrient status of patients with Alzheimer's disease: A systematic review and meta-analysis. Alzheimers Dement, DOI: 10.1016/j.jalz.2013.05.1771.

[172] Scheltens P, Kamphuis PJ, Verhey FR, Olde Rikkert MG, Wurtman RJ, Wilkinson D, Twisk JW, Kurz A (2010)
Efficacy of a medical food in mild Alzheimer's disease: A randomized, controlled trial. Alzheimers Dement 6, 1-10 e11.

[173] Shah R, Kamphuis P, Leurgans S, Swinkels S, Sadowsky C, Bongers A, Rappaport S, Quionn J, Wieggers R, Bennett D, Scheltens P (2011) Souvenaid as an add-on intervention in patients with mild to moderate Alzheimer's Disease using Alzheimers's Disease medication: Results from a randomized, controlled, double-blind study (S-Connect). J Nutr Health Aging 15, S30.

[174] Scheltens P, Twisk JW, Blesa R, Scarpini E, von Arnim CA, Bongers A, Harrison J, Swinkels SH, Stam CJ, de Waal H, Wurtman RJ, Wieggers RL, Vellas B, Kamphuis PJ (2012) Efficacy of souvenaid in mild Alzheimer's disease: Results from a randomized, controlled trial. J Alzheimers Dis 31, 225-236. 